Javier García Roca*

Universidad Complutense de Madrid

Madrid, España

groca@der.ucm.es

\title{
La función parlamentaria de control a caballo de parlamentarismo y presidencialismo $^{* *}$
}

\author{
Parliamentary oversight, a role linking parlamentarism and \\ presidentialism
}

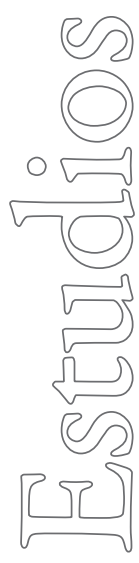

* Catedrático de Derecho

Constitucional de la Universidad Complutense de Madrid y Director de su Instituto de Derecho Parlamentario (Congreso de los Diputados$U C M)$.

\section{Resumen}

Es posible comparar presidencialismo y parlamentarismo en los controles parlamentarios. Sin control parlamentario, no puede existir democracia representativa, tampoco en el presidencialismo. Las normas constitucionales y de los Reglamentos ya reflejan esa tendencia en Iberoamérica. Esta conclusión lleva a que el clásico debate sobre ambos sistemas de gobierno deba contemplarse de una manera distinta. Hay una pluralidad de tipos presidenciales y semipresidenciales de confusa diferenciación en la realidad. El presidencialismo originario estadounidense es antiguo y difícilmente exportable. El presidencialismo iberoamericano contemporáneo se ha ido parlamentarizando. Existe actualmente un continuum en el binomio presidencialismo/parlamentarismo con diferencias de grado más que cualitativas. Se advierten tres tendencias: la presidencialización del parlamentarismo europeo, la parlamentarización del presidencialismo iberoamericano, e influencias recíprocas entre los Reglamentos parlamentarios. Pluripartidismo extremado, representación proporcional, y un entendimiento absolutista de la separación de poderes presidencial, que impida los controles parlamentarios, son rasgos incompatibles. La solución más fácil está en abandonar ese entendimiento absolutista que no garantiza bien constitucional alguno. La duración fija del mandato presidencial y la idea de que el Presidente debe responder de forma diferida y directa ante el electorado hacen imposible mecanismos de control-responsabilidad política de su figura, pero puede bastar con reforzar los de control-fiscalización para construir checks and balances y representación política en el Parlamento.

\footnotetext{
** Artículo recibido el 5 de julio de 2016 y aceptado para su publicación el 28 de noviembre de 2016
} 


\begin{abstract}
It is perfectly possible to compare presidentialism and parlamentarism with regard to controls. Without parliamentary oversight representative democracy does not exist, not even in the presidential system. Constitutional norms and Standing Orders already reflect this tendency in Latin America. This conclusion leads us to a different approach to the classic controversy on both systems of government. There are various kinds of presidential and semi-presidential systems in practice and the differences among them become confusing. The original US presidential system is somewhat outdated and difficult to export. Current Latin American presidentialism has adopted parliamentary patterns. The binomial presidentialism/parlamentarism is nowadays more a continuum with differences in degree rather than in quality. Three tendencies can be detected: European parliamentarism has evolved towards presidential leadership, Latin American presidentialism has incorporated parliamentary tools, and, finally, cross-fertilization among Parliamentary Standing Orders has developed. Extreme multi-party systems, proportional representation, and an absolutist understanding of presidential separation of powers which makes parliamentary oversight impossible are incompatible features. The easiest solution emerges from abandoning that separatist interpretation: such a strong separation on behalf of what? The fixed presidential term of office and the idea that the President should be directly accountable to the electorate and not to the Parliament make mechanisms of political responsibility especially difficult, but certain devices of control-supervision could be enough to achieve checks and balances and parliamentary political representation.
\end{abstract}

\title{
I. Objeto y aproximación
}

Dada la amplitud del objeto, las diferencias entre presidencialismo y parlamentarismo y la racionalización del primero, me aproximaré a la cuestión a través del control del Gobierno por el Parlamento, que es asimismo una forma de estudiar las relaciones entre ambos órganos constitucionales y, sobre todo, la construcción de la democracia representativa. No analizaré los distintos instrumentos de control, pues se necesitaría un tratado, me limitaré a revisar el concepto y sentido de esta función parlamentaria y a extraer consecuencias generales en el presidencialismo. Pero, esta perspectiva coadyuva a comprender la actividad de cualquier Parlamento desde la lógica de la división de poderes ${ }^{1}$, y, desde esa atalaya, visualizar también cómo regular y aplicar mejor dichos instrumentos.

Tiene indudable interés estudiar la función de control tanto en el parlamentarismo como en el presidencialismo por encima de las concretas normas de cada ordenamiento. Afrontaré una reflexión fundada en principios, expuesta de forma deductiva antes que inductiva, y ubicada por encima de las fronteras, porque el problema -creo- es esencial-

Puede verse García Roca (2000) pp. 41 y ss. Frente a entendimientos exagerados o absolutistas del presidencialismo, el epígrafe "La ilusión histórica de la separación absoluta de poderes" y el siguiente. 
mente el mismo en todos los Estados democráticos, el control constitucional del poder, aunque varíen las realidades, los sistemas de gobierno y las soluciones normativas.

He intentado pues llegar al presidencialismo iberoamericano de forma indirecta o por carambola a través de la experiencia del parlamentarismo europeo. Me parece que tiene interés, en este contexto comparado, dar a conocer la amplísima bibliografía y el largo debate de las doctrinas italiana ${ }^{2}$ y española ${ }^{3}$ sobre la función de control, con la voluntad de divulgar las discusiones principales y permitir que autores de otros países comparen con sus propias experiencias nacionales ${ }^{4}$. Los términos de esta controversia sobre la función de control pueden leerse con más detalle en un trabajo que he escrito en colaboración con Renato IBRIDO y al que reenvío 5 .

La del control parlamentario es una reflexión antigua. Pero se desarrolla con intensidad en los años setenta en Italia en torno a la vieja idea de la centralidad del Parlamento. Más tarde, en los ochenta en España y en otro contexto distinto, si no opuesto, el de prolongadas mayorías absolutas de un solo partido. La controversia doctrinal en ambos países es en el siglo XXI un debate en buena medida cerrado y con posiciones suficientemente perfiladas. De manera que cabe extraer algunas conclusiones, que -me parece- podrían tener un alcance global ${ }^{6}$.

Desde la función de control parlamentario, que nos ofrece una perspectiva democráticorepresentativa, pueden comprenderse numerosas actividades típicas de todas las Cámaras. No es un debate libresco y prescindible sino esencialmente político. Es menester advertir con claridad el papel del Parlamento en cualquier división de poderes antes de crear e interpretar las normas constitucionales, así como las de los Reglamentos parlamentarios, mucho menos frecuentadas por algunos, pero que tienen una importancia central. Un Parlamento es un Parlamento. Una Cámara tiene unas funciones principales y definitorias en cualquier forma de gobierno representativa, el control entre ellas, y también debe ser así en el presidencialismo. La función de control del Gobierno es natural y consustancial a cualquier Parlamento. Otra cosa son los instrumentos previstos en las normas para

\footnotetext{
Pueden verse, entre otros muchos, Rescigno (1968); Amato (1968); Manzella (1970); Chimenti (1974); Carducci (1996); Moretti (2005), p. 317; Lupo (2009)

3 Pueden leerse los trabajos, entre otros, Santaolalla (1982), Santaolalla (1987) pp. 219 y ss; Santaolalla (1984) capítulos I y II. También los estudios de García Morillo (1985); y García Morillo (1990) pp. 247 y ss. Así como en coautoría García Morillo y Montero (1984). Ha tenido relevancia e influjo Rubio (1993) pp. 241 y ss; y las investigaciones de ArAgón que más adelante se citan. En el número 19, monográfico, de Teoría y Realidad Constitucional, 2007, una encuesta sobre el control parlamentario con respuestas de ALBA, CAzorLa, Díez Picazo, García Fernández, López Pina, Porras y Portero en pp. 9-44, y diversos estudios.

4 Sorprende, pero evidencia la tradicional perspectiva hiperpragmática muy británica que todo un clásico como MAY (1989) no estudie las funciones parlamentarias ni en particular el control. Un enfoque que ya no siguen otros estudios posteriores. Siempre he creído, por el contrario, que nada hay más práctico que una buena teoría, si emana de la práctica.

García Roca y IBRIDo (2013) pp. 105-136.

Volví a defender la validez global de esta tesis en el Magreb. Association Marocaine de Droit Constitutionnel et Association Internationale de Droit Constitutionnel, Marrakech, "Le contrôle des gouvernments par les parlaments: évolution et état des lieux", marzo de 2016, ponencia "The function of parliamentary control in Spain and Italy: a comparative study of the concept", escrita en colaboración con Renato IBRIDO, pendiente de edición.
} 
ejercerla, que difieren en cada ordenamiento. Pero hace falta un momento de comprensión previa que oriente la decisión creadora de las normas y la aplicación de las mismas.

La idea de control parlamentario es parte de la idea más amplia de controles constitucionales (cfr Galeotti, Giannini, Aragón, Valadés...) 7 . Se ubica en la democracia constitucional comprendida como un sistema de controles entre órganos y poderes: de pesos y contrapesos recíprocos. Pretende asegurar la libertad de los ciudadanos y su confianza en las instituciones democráticas, impedir los abusos o irregularidades y arbitrariedades de los cargos públicos, y construir la representación política mediante el juego de los principios de transparencia, rendición de cuentas y responsabilidad de los poderes públicos en el ejercicio de sus funciones; porque la representación política no preexiste sino que se construye a través de partidos y ciudadanos. Ninguna de estas cosas es posible sin un adecuado control parlamentario tanto en el parlamentarismo como en el presidencialismo. Desde el primer constitucionalismo liberal, los órganos supremos deben ser representativos y venir, por definición, moderados, esto es, limitados por otros poderes. De ahí nace el germen de la rendición de cuentas de los ejecutivos. La tendencia del constitucionalismo no puede ser configurar áreas inmunes de control, pues toda inmunidad, también la gubernamental o presidencial, reclama una justificación excepcional y reforzada en un Estado de derecho y no puede derivar en un estatuto de indemnidad o impunidad.

Esta natural extensión de la idea de control parlamentario debe abarcar no solo los contenidos sino también los sujetos. El tradicional control del Gobierno debe extenderse hoy con prudencia a otros poderes públicos, a muy diversos tipos de administraciones y órganos o agencias independientes, e incluso en ciertos casos a algunos poderes privados cuya actividad incida en el interés general, o tenga un punto de conexión con actividades públicas ${ }^{8}$.

\section{Algunos rasgos generales de la teoría del control parlamentario ${ }^{9}$}

Recordemos simplemente algunas ideas bien conocidas para seguir avanzando. Durante mucho tiempo, hemos pensado que la función de control no se podía definir o solo podía hacerse de manera residual y negativa, abarcando todo lo que no fuera función financiera y presupuestaria o función legislativa, dada la ausencia de un parámetro de enjuiciamiento,

Cfr García Roca y Ibrido (2013). Siguiendo, entre otros, elaboraciones previas de Galeotti (1962) pp. 319 ss.; y Giannini (1974) pp. 1263 ss; Aragón (1986), pp. 9 y ss; ValadÉs (1998)

8 BARBERA (1999) pp.79-80, advierte que la función de control puede extenderse a todos los sujetos, incluso poderes privados que tengan influencia en asuntos públicos, si bien la presencia de ciertas garantías puede decantar límites. Es notorio en España el caso de las comparecencias parlamentarias de los presidentes de dos relevantes empresas, Telefónica y Endesa, que revisó en amparo el Tribunal Constitucional (STC 177/2002, de 14 de octubre). El Reglamento de la Cámara de Diputados de Chile (artículo 299) faculta a las comisiones parlamentarias de investigación para citar a los directivos de empresas en las que el Estado tenga capital o representación. También el artículo 158.I. 20 de la Constitución de Bolivia.

ManZella (1991), especialmente p. 351-353, argumenta la extensión del control a todos los poderes públicos, incluidas las Administraciones públicas, autoridades administrativas independientes o a la televisión pública. Ahora también a las instituciones europeas. Vid asimismo ManZella (1970) ob.cit.

In extenso, García Roca y IBRIDo (2013) ob.cit. 
estable y normativo, de la actividad del Gobierno. Pero no es así, cabe hacerlo, aunque sea de una manera flexible y algo lábil, y no resulte una definición unánime sino mayoritaria en la doctrina científica.

Ahora bien, "control" es un sustantivo que requiere ser calificado por un adjetivo o completado por el significado de otro sustantivo: político, jurídico, información, sanción, fiscalización, verificación, injerencia, responsabilidad política... Esta indeterminación evidencia el carácter poliédrico o de geometría variable del concepto. Es así habitual diferenciar entre control-fiscalización y control-responsabilidad politica, como división básica, aunque las terminologías varíen en los países.

Otro problema contemporáneo deriva de la misma amplitud del concepto de control, que corre el riesgo de cubrir toda la actividad parlamentaria en algunos análisis extensivos, algo que es poco operativo a efectos clasificatorios y conceptuales, por su excesiva amplitud, precisamente al abarcar casi cualquier herramienta. Pero, en todo caso, hemos superado un concepto estricto de control, ligado a las sanciones o incluso a las injerencias, que resulta no menos impracticable en la realidad por su pequeñez. El concepto de control debe ligarse - de forma intermedia- a dos cosas: la fiscalización de la acción del gobierno y la responsabilidad politica. No obstante, admitiremos que la función de control se sustancia en actividades y actos parlamentarios con muy distinta forma y contenido.

De forma complementaria, demandar la responsabilidad politica de los gobernantes no es necesariamente lo mismo que exigir su dimisión como una sanción o injerencia ${ }^{10}$. La palabra "responsabilidad", etimológicamente, exige la obligación de "responder" en sede parlamentaria, pero existen grados progresivos en la responsabilidad política (comparecer, informar, explicarse, contestar) de los gobernantes antes de llegar a la inmolación que entraña el cese, según ha estudiado bien Rafael Bustos, tras analizar la larga experiencia británica donde el cese a menudo tampoco se produce ${ }^{11}$. Answerable to no es lo mismo que answerable for según una terminología inglesa muy clásica ${ }^{12}$. La teoría de la democracia representativa debe adecuarse a la realidad de nuestros días y evitar las frustraciones: el parlamentarismo rara vez produce la dimisión ministerial y, menos aun, el cese de todo el Gobierno. El clásico principio de la responsabilidad ministerial debe ser reinterpretado. El resultado del control parlamentario debe ser la respuesta del Gobierno en el Parlamento a

10 En este sentido, los trabajos de Joaquín GARcía MoriLlo antes citados frente a la tesis de Fernando SANTAOLALLA en estudios igualmente mencionados. En Italia, igualmente, una primera concepción, sostenida especialmente por Massimo Saverio Giannini, asociaba "control" con "sanción" en GiANNini (1965) p. 332. La idea de control como "injerencia” conecta con el término anglosajón "control", que designa una actividad de inspección que precede al acto o actividad sometida a enjuiciamiento, en cambio, su comprensión como "verificación" o "fiscalización" se relaciona con el término "scrutiny" o mejor "oversight" en cuanto entraña un enjuiciamiento sucesivo o la revisión de un acto. Vid Ferrari (1953) pp. 243-244.

11 Debe verse la excelente monografía de Bustos (2001), cuya lectura recomiendo. Con anterioridad, distinguía asimismo diversos grados de responsabilidad politica, distintos a la sanción, MANZELLA (1991) p. 353, quien relativiza la remoción del cargo como sanción típica del control, y asevera que es una medida inadecuada para una responsabilidad política difusa, en vez de institucional. Debe ser -concluye- más una influencia sobre el controlado que un poder directo.

12 Vid Finer (1976) vol. XXXIV, p. 393, polemizando con JenNings y KeITH sobre el alcance de esta convención. La tesis se continúa en la obra de Woodhouse, centrada en la acountability, entre otros estudios, WoodHouse (1993) 46 (3), pp. 277-292. 
instancia de las minorías con las adecuadas dosis de inmediatez, publicidad y transparencia. Con esto puede bastar. Pero es perfectible como todo en democracia.

La cuestión es pues bastante compleja, tanto como lo es el parlamentarismo en un Estado de partidos, desde hace mucho tiempo impulsado -y a la vez limitado- por el juego entre mayoría y minorías. El Estado de partidos ha transformado las reglas y principios del parlamentarismo ${ }^{13}$. También lo ha sometido a una teatralización o escenificación de los debates ${ }^{14}$, incluidos los de control, pensados en su ejercicio de cara a los medios de comunicación social antes que a la discusión en la propia sede parlamentaria. Solo como un icono -o un mito- el parlamentarismo es ya la búsqueda de la verdad o del logos a través de procedimientos contradictorios mediante el debate entre mayorías y minorías ${ }^{15}$.

El fenómeno se resiste, por todo ello, a un análisis estrictamente jurídico, al igual que ocurre con la democracia representativa y el funcionamiento de los partidos. El control parlamentario tiene una naturaleza política y no jurídica como ocurre con el control de constitucionalidad ${ }^{16}$. Está en manos de unos sujetos políticos, los partidos y los Grupos. Sobre todo, carece no solo de un parámetro de control normativo -como se ha dicho ya- sino siquiera estable. Así pueden verificarse y denunciarse los incumplimientos del programa electoral del Gobierno, pero también manejarse -por sustitución- como parámetro de control el propio programa de la oposición ${ }^{17}$. Controlar al Gobierno por no hacer lo que la oposición querría hacer de estar en el poder y haber vencido las elecciones, por contradictorio que ello resulte. Cómo ponerle puertas al campo...

Cuanto he dicho puede parecer evidente, pero conviene caer en la cuenta de que muchos de los mecanismos de control actuales fueron diseñados y creados en una época en que

13 Son numerosos los trabajos, recordaré Sonnheimer (1980) pp. 5-21; y LeibHolz (1971).

14 Manuel Marín, siendo Presidente del Congreso de los Diputados y próximo a dejar el cargo, en su conferencia inaugural de reapertura del Instituto de Derecho Parlamentario, UCM, 29 de octubre de 2007, "Gobernabilidad y Parlamento en el siglo XXI".

15 Véase p.ej. Kriele (1980) Capítulo IV "Parlamentarismo", donde se revisan dos interpretaciones clásicas del parlamentarismo en los años veinte del siglo XX: Carl Schmitт y Ernst Troeltsch. Se afirmaba que la base del parlamentarismo "es el traspaso de la idea de proceso jurídico al proceso político de la legislación", publicidad y discusión. La discusión sustituye a la fuerza. Unas ideas que no fueron abandonadas - afirma-con la democratización del Parlamento, pero las decisiones esenciales se toman fuera de las Cámaras. Esta argumentación schmittiana -diceliberó el camino para la lucha contra el parlamentarismo: idealizarlo para desenmascararlo. KRIELE insiste en el proceso dialéctico de discusión.

16 Ha seguido con acierto, en España, este enfoque Aragón (1986). También Aragón (1994) epígrafes "La función del Gobierno y la función de las Cámaras. El significado actual del control parlamentario”. ARAGón (1985) pp. 13 yss.

Previamente, el mismo planteamiento en Italia, Giuseppe Ugo ResCigno en su temprana monografía La responsabilitá política Rescigno (1968). En su Corso di Diritto Pubblico Rescigno (1979) epígrafe "La funzione dicontrollo politico del Parlamento" p. 386 y ss; concluía que el control parlamentario es un control político, completamente diferente del control jurídico, precisamente porque no está vinculado a criterios objetivos y predeterminados sino que depende de la libre voluntad de los partidos políticos, cada fuerza política crea sus criterios. La coincidencia con las posteriores posiciones españolas es manifiesta.

17 Miguel Ángel PreSNO: "Sistema de partidos y control parlamentario" en Revista de las Cortes Generales, n 46, 1999 , pp. 94, siguiendo elaboraciones de Javier GARCía Roca (“El control del Gobierno...”, ob.cit., p. 172) referidas a que el control de la oposición podía fundarse en la "pretensión de imponer un parámetro alternativo o de sustitución", desarrolla la idea del control como unos instrumentos encaminados a formar una dirección política diferente a la actual y expresión de una nueva mayoría. Una idea que es también frecuente en Italia. 
lospartidos politicos no estaban consolidados y aquí comienzan las contradicciones entre normas y realidades y algunas de las ineficacias que conviene reparar. Para su recto funcionamiento, los instrumentos de control deben ser revisados y ajustados constantemente, corrigiendo defectos e insuficiencias y superando las tradicionales inercias parlamentarias. No es frecuente que ocurra así.

De forma complementaria, solo unas pocas de estas herramientas suelen estar en las manos de los parlamentarios a título individual (preguntas, solicitudes de información, enmiendas...), por el contrario, la mayor parte pertenecen -de forma creciente- a los Grupos parlamentarios o bancadas, al igual que el tiempo de participación en los debates. Si bien la intensidad o grado difiere en los diversos Reglamentos, el fenómeno de la "agrupación" excesiva es el mismo. Pero la solución no es tan sencilla como atribuir todos los mecanismos a la titularidad de los Grupos, en cuanto personificación parlamentaria de los partidos, desaprovechando los esfuerzos individuales de los representantes y su libertad de mandato libre y no vinculado. Es menester encontrar un adecuado equilibrio entre parlamentarios y Grupos en los Reglamentos parlamentarios ${ }^{18}$. Si no queremos desaprovechar esfuerzos y capacidades y alcanzar un parlamentarismo huero, mediocre, predecible.

Por otro lado, las herramientas y procedimientos parlamentarios tienden a poseer un carácter versátil, intercambiable ${ }^{19} \mathrm{y}$ multifuncional ${ }^{20}$. Sirven para varias cosas en la actividad o el funcionamiento de las Cámaras, y no siempre para lo mismo, ni siquiera al tiempo, si estos instrumentos se analizan con realismo. Así no es extraño que los parlamentarios formulen preguntas no para recibir información, que no esperan realmente obtener, o abrir una rendición de cuentas, que no siempre se consigue, sino simplemente para mandar el texto a la prensa y permitir que el representante contacte con su electorado. También es frecuente que las enmiendas individuales se presenten no con la voluntad de participar en la función legislativa, pues no se espera que sean aceptadas, sino como una técnica de control de las minorías sobre la dirección política de la mayoría con la voluntad de mantener informada a la opinión pública y denunciar los excesos o errores de la mayoría. Otro tanto semejante ocurre con el control en materia presupuestaria, que es parte también de la función presupuestaria y financiera, y pese a que esta función se monopolice por los Gobiernos tanto en la iniciativa como en la aprobación. O con las comisiones parlamentarias de investigación donde más que pretenderse esclarecer los hechos, cosa que harán los tribunales más adelante al dilucidar la responsabilidad jurídica, las minorías tienden a contentarse con dar publicidad a algunos escándalos en la acción de gobierno y dañar a la imagen pública de sus responsable; con eso puede bastar.

18 Vid García Roca (1997) pp. 225-278; en el mismo sentido, García Escudero (2011) pp. 205-242

19 Héctor FIX-XAmUdio subraya el carácter intercambiable de las instituciones procesales en los sistemas de gobierno, de manera que instituciones creadas en el parlamentarismo pueden usarse en el presidencialismo y a la inversa, como una de las conclusiones más importantes del libro de VALADÉs (1998) p. XXI. Insistieron en la versatilidad de los procedimientos parlamentarios dentro del parlamentarismo Molas e Pitarch (1987).

20 Recuerda que el concepto de control es funcional y puede cumplir diversos objetivos FERNÁNDEZ SARASOLA (2000) pp. 89 ss. 
¿Cuál es la ocassio? La oportunidad o circunstancia que provoca el control puede variar. En España, la reflexión sobre el control comenzó a mediados de los años ochenta en tiempos de largas mayorías absolutas del PSOE. La hegemonía gubernamental de un partido muy disciplinado y con un fuerte liderazgo presidencial, hizo pensar en la necesidad del control parlamentario ante el interés general en mantener un equilibrio en la división de poderes. Sin control parlamentario no existe democracia representativa. La proposición es más cierta cuando mayor sea el predominio gubernamental según ocurre en el presidencialismo ${ }^{21}$.

Esta situación española de fuerte desequilibrio de poderes en provecho de la preeminencia del Gobierno, si no del Presidente directamente, por la ausencia de contrapesos parlamentarios eficientes - una primacía gubernamental es inevitable- coincide de alguna manera con la del fuerte hiperpresidencialismo iberoamericano que tiende a crear un tipo de democracia más elitista y menos participativa. Los propios orígenes liberales del presidencialismo en los Estados Unidos del siglo XVIII son -lógicamente- elitistas.

En otro escenario distinto, en Italia, la permanente existencia de gobiernos de coalición de centro izquierda, a causa de la fragmentación de la representación, y siempre con exclusión del partido comunista, llevó igualmente a incrementar las posibilidades de ejercicio del control parlamentario ${ }^{22}$. Una oposición excluida permanentemente del Gobierno y sin posibilidades reales de alternancia debía tener al menos como sede natural de su actividad el Parlamento. La situación no era la misma que en España, ya que el Gobierno no era tan poderoso en Italia, pero la fragmentación de la representación política llevó igualmente a incrementar el control parlamentario.

Estos dos escenarios hacen pensar que control y Parlamento son, en una democracia representativa, el hábitat natural de la oposición y las minorías, y un contrapeso imprescindible del eje mayoría-Gobierno. En suma, el debate sobre el control puede surgir con Gobiernos monocolores o de coalición y desde la -perdida- centralidad del Parlamento o desde un parlamentarismo o un presidencialismo con robusto liderazgo presidencial.

¿Qué tiene entonces el fenómeno en común? Concluiremos que lo realmente relevante es la finalidad. Todo control parlamentario supone una decidida voluntad de un Parlamento de frenar los excesos del poder público y al tiempo contribuir a crear una opinión pública libre, mediante una constante fiscalización de la acción gubernamental, que obligue al

21 El presidencialismo incide en el tipo de democracia. Carlos S. Nino sostiene que el hiperpresidencialismo argentino produce una democracia elitista o pluralista -según las pautas estadounidenses- y magros mensajes electorales muy personales, mientras lo deseable es un modelo de democracia más participativa y deliberativa, algo a lo que algunos instrumentos del parlamentarismo pueden coadyuvar. Vid "El hiperpresidencialismo argentino y las concepciones de la democracia” en Nino et al (1992) pp. 17-79. En la misma obra, GARGARELLA (1992) pp. 81-105, recuerda los ingredientes elitistas de la Constitución estadounidense, temerosa de los resultados derivados de los excesos de la voluntad colectiva y de las asambleas populares. Por eso se diseñan en ella numerosos límites contramayoritarios. El sistema presidencialista en Iberoamérica acoge ese carácter receloso de las mayorías que expuso Madison.

22 Cfr García Roca y Ibrido (2013) ob.cit. 
Gobierno a informar a la Cámara y rendir cuentas, permitiendo el derecho de los ciudadanos a recibir información ${ }^{23}$.

Es verdad que el presidencialismo fue diseñado, como ilustra "El Federalista", intentado concentrar mucho poder en un solo hombre ${ }^{24}$. Pero es no menos cierto que los padres fundadores no pretendieron edificar una forma de gobierno desprovista de controles, todo lo contrario, intentaron sobre todo escapar de la monarquía absoluta mediante un sistema de contrapesos presidenciales.

Dejaremos a un lado los decisivos controles jurisdiccionales independientes, así como los derivados de la concurrencia de los medios de comunicación social en una situación de pluralismo externo. Ahora bien, sin este tripode de controles -parlamentario, judicial e informativo- el control parlamentario por sí mismo sirve de muy poco. Por eso en las Repúblicas donde la independencia judicial se viola o está seriamente amenazada, no suele tampoco existir pluralismo informativo, el control parlamentario es débil o inexistente, y los derechos políticos de las minorías tienden a desaparecer. Son vasos comunicantes amenazados por la lógica autoritaria o totalitaria de un Gobierno que impide el control de su poder. El descenso de los niveles de uno de ello provoca antes o después el de los otros dos, por las conexiones que existen en el flujo de todo poder.

Por último, pero en directa conexión con cuanto precede, laparticipación de las minorias -como verdaderos sujetos o titulares del contro ${ }^{25}$ y la atribución por los Reglamentos de las Cámaras de iniciativas y facultades de control a los parlamentarios y los Grupos es una condición necesaria para la existencia del control pero dista de ser suficiente. Las normas reguladoras del control pueden ser válidas pero no eficaces. Su eficacia requiere de la colaboración de la mayoría ${ }^{26}$, que debe colocar a la oposición y a las pequeñas minorías en una situación en la que puedan ejercer el control ${ }^{27}$. Esta actitud democrática constituye la misma cultura política del parlamentarismo -en realidad de todo Parlamento, también en

23 VALADÉS (1998) nos advierte que "controlar al poder" es un "enunciado en apariencia paradójico" y lo que "en el fondo se agita es la preocupación secular por evitar los excesos". En efecto, impedir el exceso es consustancial -a mi entender- a todo verdadero Derecho Constitucional. Más adelante Valadés (1998) dirá (p. 17) "controlar al poder es un acto de poder" y -siguiendo a CRISAFULLI- afirmará que el poder de gobernar corresponde a la mayoría y el de controlar a la minoría.

24 Hamilton nos decía: que la autoridad ejecutiva debía estar encomendada a un solo magistrado antes de analizar pormenorizadamente todas las facultades del Presidente; que un ejecutivo vigoroso no es incompatible con los principios republicanos; que los actos de un solo hombre se caracterizan por su mayor decisión y diligencias que los de un colegio. Vid Hamilton, MAdison y JaY (1943), $5^{\text {a }}$ reimpresión, los artículos originales de 1787 publicados en prensa y luego como libro; en especial los capítulos LXVIII y LXIX

25 Cfr García Roca y Ibrido (2013). Sobre el rol de las minorías pueden leerse García Roca (1997) y López Guerra (1996). Acerca del papel de la minoría ha tenido gran influjo en España VergotTini (1968) pp. 388 y ss; previamente, Vergottini (1973) y Vergottini (1993) pp. 403-417. Su influencia es manifiesta en Juan Fernando López Aguilar (1991) también en Presno (1999). Puede verse Sánchez navarro (1997).

26 Una tesis sobre papel de la mayoría es EMBID (1992) pp. 10 y ss., quien identifica hasta seis formas de usar la palabra control. Otra tesis orgánica en García Fernández (1994) pp. 31 y ss; y García Fernández (1997) pp. 195 y ss.

No ha ocurrido así en España durantela brevísima XI Legislatura, disuelta automáticamente al no poder investir el Congreso de los Diputados a un Presidente, y donde el Gobierno en funciones se negó a someterse al control de las Cortes Generales con razones de escasa enjundia, pero acaso tampoco se limitaron debidamente el alcance de su control ni las iniciativas legislativas. Puede leerse García Roca (2016). La controversia ha concluido con la presentación de un conflicto entre órganos constitucionales ante el Tribunal Constitucional. También CARRILLO (2016) 
el presidencialismo-y es parte indefectible de una dirección política de Estado. Conforme a esa cultura democrática, es menester, primero, introducir lógicas previsiones normativas en los Reglamentos que faciliten las iniciativas de las minorías v.gr. en la creación de comisiones parlamentarias ${ }^{28}$ o en la presentación de preguntas y mociones, aunque las decisiones posteriores queden en manos de la mayoría. Más adelante, son precisas decisiones regulares de los órganos de dirección de las Cámaras - que controla la mayoría- en la organización de los trabajos: admisión y calificación de los escritos, formación proporcional de las comisiones, negociación de las agendas y programas, admisiones o rechazos de las comparecencias, etc.

En España, el Tribunal Constitucional ha hecho una labor impagable en el control en amparo constitucional de la regularidad de muchas estas decisiones parlamentarias de la mayoría con cobertura en el derecho fundamental de los cargos públicos representativos al ejercicio del cargo y a desempeñar sus funciones (artículo $23.2 \mathrm{CE}$ ), para permitir a los parlamentarios construir su relación de representación política de los ciudadanos ${ }^{29}$. Mediante diversos procesos constitucionales y técnicas existen ya propuestas fundadas de trasladar a Iberoamérica este control externo, limitado y judicializado del Parlamento en defensa de los derechos políticos, según hemos auspiciado desde el Instituto de Derecho Parlamentario de la Complutense ${ }^{30}$.

La mayoría no es todo el Parlamento. El Parlamento es la casa de las minorías, de la oposición, a diferencia del Gobierno y la Presidencia que es el lugar de la mayoría ${ }^{31}$. El debate italiano y español sobre el control ha concluido señalando que el verdadero sujeto activo son necesariamente las minorías parlamentarias.

\section{III. ¿Son parlamentarismo y presidencialismo términos homogéneos a efectos de comparación en la función de control?}

¿Son parlamentarismo y presidencialismo contextos tan distintos? ¿Hasta el extremo que no quepa comparar los instrumentos de control? ${ }^{32}$

28 Los artículos 87 y 88 del Reglamento de la Cámara de Senadores de Argentina prevén la creación de comisiones de investigación en el ejercicio de las funciones de fiscalización y control nada menos que a instancias de dos terceras partes de los miembros.

29 Cfr García Roca (1999).

30 Cfr la tesis doctoral, pendiente de edición, de Navas (2014); y, respecto de El Perú, la tesis en curso de confección de Eddie Cajaleón que codirijo con César LANDa.

31 La idea se expuso bien entre nosotros por Alfonso Fernández Miranda en el prólogo a Ignacio Torres. FerNÁNDeZ Miranda (1987). Es clásica en el Reino Unido. Resulta muy útil leer MCKaY y JoHson (2010) quienes recuerdan "currently, twenty days on the floor of the House of Common are devoted to motions tabled by opposition parties...."

32 Ratifica mi confianza en la tesis comparatista que propongo MCKAY y JoHSON (2010) quienes afrontan un estudio comparado de los sistemas del Estados Unidos y el Reino Unido, en particular sobre "Scrutiny and oversight" el capítulo 7 . 
Tradicionalmente hemos explicado que el presidencialismo entraña una separación de poderes rígida, fundada en el poder de una persona que personifica la nación ${ }^{33}$, mientras el parlamentarismo supone una división de poderes flexible basada en la integración de Gobierno y Parlamento mediante un conjunto de relaciones que arrancan de una previa relación de confianza ${ }^{34}$.

Una explicación clásica y articulada en torno a varios ingredientes muy conocidos. Así el presidencialismo entraña la elección directa del Presidente por el pueblo, lo que refuerza su legitimidad y autoridad. Un ejecutivo monista donde el Presidente de la República es Jefe del Estado y también Presidente del Gobierno. La imposibilidad de disolución anticipada de las Cámaras, y una elección de las mismas y del Presidente que no son contemporáneas y, en consecuencia, pueden no ser simétricas las mayorías. La ausencia de una moción de censura que derribe al Presidente y por ende al Gobierno. La inexistencia de la cuestión de confianza a instancias del Presidente. La incompatibilidad de los cargos de Secretario de Estado o Ministro y parlamentario. Instrumentos de control parlamentario específicos como son la ratificación por el Senado de ciertos nombramientos y actos presidenciales, controles presupuestarios y sobre la deuda pública, y, en su caso, el impeachment o la acusación y juicio político por una violación grave de la Constitución como única forma de provocar una salida anticipada del Presidente ${ }^{35}$. También la facultad presidencial de veto de las leyes y un largo etcétera de diferencias de las que se han ocupado muchas veces la doctrina científica en ambos hemisferios. En definitiva, un Presidente y un Gobierno separados del Parlamento.

Existen en la práctica tantos presidencialismos -y semipresidencialismos y parlamentarismos- como países. Así ocurre desde luego en Iberoamérica ${ }^{36}$. Hay bastantes rasgos actuales de los diversos presidencialismos iberoamericanos muy distintos del modelo original estadounidense ${ }^{37}$. Recordemos algunos. Las amplias facultades de iniciativa le-

33 Vid Hamilton, Madison y Jay (1943) pp. 288 a 297. Pero conviene no olvidar el carácter liberal, y elitista o escasamente democrático de sus ideas, porque no pensaba en una elección directa del Presidente por el pueblo sino en una elección indirecta a través de compromisarios. El poder de selección del Presidente debía concederse a "los hombre más capaces de analizar las cualidades que es conveniente poseer para ese puesto", un pequeño número de personas escogidas por sus ciudadanos entre "la masa" (pp. 288-289).

34 Un gobierno que emerge "de" y responde "ante" el Parlamento, en palabras de Epstern (1968) vol. II, p. 419. Previamente, entre otros, Redslob (1923) pp. 511-539 y Redslob (1924); Gouet (1932) pp. 179-243 ; о Mirkine-Guetzevitch (1931) pp. 7-57; Galizia (1972). Revisé estos trabajos en García Roca (1985).

35 Acabamos de asistir a la apertura del proceso de destitución o impeachment de la Presidenta de Brasil, Dilma Rousseff, el 12 de mayo de 201, un juicio político ante el Senado -la responsabilidad por delito es ante el Tribunal Supremo- que abre el Congreso de los Diputados por dos tercios y que concluirá en una votación final del Senado transcurridos 180 días, pero que conlleva la suspensión automática y el traspaso del poder al Vicepresidente (artículos 85 a 86 Constitución). Se ha abierto un debate sobre el sentido político de un proceso que permite remover a una presidenta elegida por el pueblo en virtud de genéricas acusaciones sobre la situación económica y maniobras fiscales.

36 Esta es la tesis de mi -desaparecido y querido- amigo CARPIZo (2007) en especial pp. 193 y ss, las citas posteriores son de esta obra. CARPIZo desarrolló varias tipologías de los presidencialismos iberoamericanos. Distinguía entre presidencialismos: puros, predominantes, atemperados, con matices parlamentarios, y parlamentarizados. Desde la perspectiva de la realidad, presidencialismos: hegemónicos, equilibrados, débiles. No siempre es sencilla la diferencia. Es clásico su CARPIzo (1978).

37 Entre otras muchas descripciones de las relaciones entre ejecutivo y legislativo en el presidencialismo de la región y de la introducción de instrumentos propios del sistema parlamentario, puede verse las síntesis de KRSTICEVIC (1992) p. 144 y ss. 
gislativa de los Presidentes en muchos países, a veces exclusiva en materia de gasto público y presupuestos ${ }^{38}$. Los poderes extraordinarios en los estados de emergencia que permiten al Presidente suspender garantías y disponer de prerrogativas. La amplitud del veto presidencial -total o parcial- de las leyes, que le ofrece una mayor discrecionalidad que en Estados Unidos. La habilitación legislativa del Presidente que le permite dictar decretos con fuerza de ley en una suerte de delegación legislativa ${ }^{39}$. La necesidad del refrendo de los actos presidenciales, aunque no parece sea un verdadero control. El desfallecimiento de los controles judiciales independientes en bastantes casos. La debilidad de los controles senatoriales. La flaqueza del federalismo como división vertical de poderes y, ligado a ella, los problemas en la financiación de los Estados. La debilidad de los parlamentos y su escasa auctoritas frente a la fortaleza del Presidente. La facultad de los Ministros de participar -sin voto- en los debates parlamentarios. La elección al mismo tiempo, pero de forma separada, del Parlamento y del Presidente en algunas repúblicas. El debate sobre la supresión de la regla de no reelección, que podría generar presidencias indefinidas o demasiado prolongadas, y un largo etcétera de cosas. Algunos de esos ingredientes - pero no todos- son reflejos de una vieja tendencia al caudillismo - de herencia hispánica- o al autoritarismo en unos países ${ }^{40} \mathrm{y}$ al hiperpresidencialismo en otros.

Una diferencia esencial entre los presidencialismos -de gran relevancia para este estudio- es que muchas constituciones de Iberoamérica han introducido facultades típicas del sistema parlamentario como límite al hiperpresidencialismo. América Latina parece presentar "un clima menos propicio para el desarrollo del régimen presidencial que los EEUU"41

Del mismo modo, existen importantes divergencias en las regulaciones presidenciales en cada país de esa amplia región que es Iberoamérica. No todas esas notas diferenciales que he enunciado antes con carácter general están presentes en todos los Estados. Unos desarrollos normativos desiguales son inevitables ante tantos poderes de reforma constitucional, plenamente soberanos, que no vienen obligados a seguir un único tipo ideal de presidencialismo. Así v.gr. es notoria la existencia en Argentina de un Jefe de Gabinete de Ministros ${ }^{42}$ que puede ser censurado por el Congreso. Un control- responsabilidad política típicamente parlamentario.

In extenso, debe verse el trabajo de NogueIra (1988) pp. 125-161.

38 La Constitución de Chile (artículo 65), con origen en un contexto autoritario, concede al Presidente de la República iniciativa exclusiva en materia financiera, presupuestaria y de división política o administrativa del país.

39. Ver la Constitución de Chile (artículos 32.3 y 64). En Venezuela, donde se ha producido un abuso de esta técnica, esta posibilidad ya se preveía en la Constitución de 1945 y se mantuvo prácticamente indemne en la Constitución Bolivariana de 1999, tras la asamblea constituyente como legislación delegada mediante ley habilitante de la Asamblea Nacional, sin necesidad de urgencia, y sin la previsión constitucional de controles parlamentarios, no obstante, quepa un control ante la jurisdicción constitucional.

40 Nohlen (1991) pp. 43 y ss, argumentaba que este posible autoritarismo no procede únicamente del presidencialismo y advertía de los riesgos de la "tentación parlamentaria", porque las formas de gobierno deben adaptarse a los países y circunstancias históricas. Pero esta posición del maestro de Heildelberg no deja de contestar una pregunta formulando otra.

41 Nogueira (1988) ob. cit., p. 154.

42 En Argentina, este Jefe de Gabinete de Ministros tiene responsabilidad política ante el Congreso de la Nación, y debe concurrir al menos una vez por mes y alternativamente a cada una de sus Cámara, pudiendo ser interpelado a efectos de una moción de censura y removido por mayoría absoluta de sus miembros (artículos 100 y 101 Constitución de Argentina). Esta sesión informativa se regula con detalle en el Reglamento de la Cámara de Diputados (artículos 198 
Me pregunto pues si esta distinción clásica, parlamentarismo versus presidencialismo, sigue siendo una summa divisio o, por el contrario, estamos cada vez más ante un continuum: un mismo fenómeno jurídico con distintos escalones en laparlamentarización de la división de poderes y diferencias de grado. Al igual que se ha construido la teoría de la descentralización territorial y de las formas de Estado según la posición de Hans Kelsen en su Teoría General del Estado.

La presencia de dos modelos distintos de partida, uno en cada extremo de la escala, es, sin embargo, un criterio relevante. Muchos autores han sostenido, con razones de peso, que esta diferencia permite por sí misma disociar ambas cosas, dada la entidad de sus diferencias ${ }^{43}$; recomendando profundizar en la filosofía o el espíritu de cada uno de ellos para perfeccionarlos en vez de afrontar la imposible mezcla de agua y aceite como magnitudes de distinta densidad. Quizás debiera ser así, reconstruyendo la erección del dogma, y así lo he creído durante mucho tiempo. Pero cada vez albergo más dudas respecto de la oportunidad de esta tesis, y en todo caso no parece que las normas constitucionales iberoamericanas recientes anden ese camino. No deberíamos seguir construyendo una teoría de los sistemas de gobierno alejada de la realidad y de las normas.

Diferenciar presidencialismo y parlamentarismo hasta disociarlos, por otro lado, obliga a hacer inagotables y complejas tipologías internas a uno y otro modelo. Diversos tipos de presidencialismos de contornos imprecisos y convencionales que no dejan de generar confusión. ¿Cuántos presidencialismos existen en Iberoamérica y cuántas clasificaciones se han hecho?

Acaso sea más realista, concluir que puede haber tantos escalones del binomio parlamentarismo/presidencialismo como países y regulaciones, y, en consecuencia, numerosos híbridos o sistemas mixtos. De la misma manera, la doctrina ha renunciado ya a ofrecer un tipo universal de Estado federal, ante la multiplicidad de variantes, y advierte que federal es cualquier Estado descentralizado conforme a un principio federal. Admitiré, no obstante, que estas tesis gradualistas son lábiles y presentan algunos inconvenientes, si bien -estimo- que de menor entidad. Me contentaré por ahora con afirmar que es perfectamente posible comparar ambos sistemas, parlamentarismo/presidencialismo, al estudiar la función de control tras decantar algunos imprescindibles límites.

El dato normativo de que normalmente no exista en el presidencialismo la censura ministerial o la cuestión de confianza, como herramientas extraordinarias de controlresponsabilidad politica del Presidente, no impide que puedan existir otras muchas herramientas de control-información muy semejantes en ambos modelos como son, entre

a 202); otro tanto se hace con los informes de los Ministros y Secretarios del poder ejecutivo (artículos 203 a 210). La asistencia de ambos se regula en los artículos 214 a 215 del Reglamento de la Cámara de Senadores que incluso detallan que la exposición del informe del primero no puede ser leída.

43 Se defiende esta tesis en el estudio de Aragón (1998). También, en el mismo sentido, Carpizo (2007) y muchos otros relevantes autores.

En sentido contrario, entre otros, VALADÉs (1998). 
otras, comparecencias o solicitudes de información de los miembros del gobierno, de uso mucho más frecuente que las primeras ${ }^{44}$.

Por lo demás, basta un sencillo cambio de las normas constitucionales o del Reglamento parlamentario, para que algunas de las diferencias de ambos sistemas desaparezcan o se amortigüen como ya ha ocurrido en varios países de la región que p.ej. establecen: una investidura del Presidente del Consejo de Ministros (figura diferente al Presidente de la República), incluso acompañado de los demás Ministros ${ }^{45}$ después de ser nombrados por el Presidente, o admiten la moción de censura del Consejo de Ministros o de los Ministros por separado o del Vicepresidente ${ }^{46}$, o de los funcionarios que no comparecieren, o establecen preguntas e interpelaciones y la obligatoriedad de la comparecencia de los Ministros ${ }^{47}$, o admiten la disolución anticipada del Congreso por el Presidente de la República en ciertos casos tasados ${ }^{48}$.

Ahora bien, es evidente que no deben perderse de vista estos dos diferentes contextos y sistemas de gobierno. La rígida separación de poderes -y el personalismo- que entraña el presidencialismo "dificulta una interacción cercana" entre el Congreso y la Presidencia ${ }^{49}$. Pero no siempre la impide.

En suma, las reflexiones comparadas en materia de control en uno y otro sistema creo que son metodológicamente posibles y muy útiles, primero, por la similitud de buena parte de los instrumentos en que el control se articula en los Reglamentos parlamentarios, pero no de todos, y desde luego por la semejanza de los supuestos de hecho y experiencias en numerosos conflictos políticos: los abusos inherentes a todo poder.

Pero también es así, puesto que la misma diversidad de ambos modelos teóricos se ve seriamente atenuada por tres tendencias en la evolución de ambos sistemas de gobierno que intentaré sintetizar.

44 El artículo 71 de la Constitución de Argentina prevé las comparecencias y establece que cada una de las Cámaras pueden hacer venir a los Ministros para recibir los informes e explicaciones que estimen convenientes.

45 Artículo 82 del Reglamento del Congreso de la República del Perú sobre la investidura del Consejo de Ministros. Si bien el nombramiento del Presidente del Consejo y de los Ministros corresponde al Presidente de la República según el artículo 122 de la Constitución. No obstante, el Presidente del Consejo debe exponer la política general de su gobierno al Congreso y pedir la confianza (artículo 130 de la Constitución). Un modelo muy parlamentario y de doble confianza.

46 El artículo 97 de la Constitución del Perú reconoce la facultad del Congreso de iniciar investigaciones sobre cualquier asunto de interés público. El Reglamento del Congreso de la República del Perú, dedica a la función de control el artículo 5 y un muy completo y sistemático Capítulo VI, Sección $2^{\mathrm{a}}$ (artículos 82 al 92). La censura del Consejo de Ministros o de los Ministros por separado y el rechazo de la cuestión de confianza en los artículos 132 y 133 de la Constitución y en el artículo 86 del Reglamento. La Constitución de Ecuador (artículo 131) reconoce la censura de los Ministros y de un conjunto de autoridades por mayoría absoluta de la Asamblea Nacional y a instancias de una cuarta parte de sus miembros. La Constitución de Venezuela prevéla moción de censura del Vicepresidente (artículo 240) y de los Ministros (artículo 246) por las tres quintas partes de los miembros de la Asamblea Nacional, y obliga a los Ministros a presentar anualmente una memoria "razonada y suficiente" de su gestión o despacho a la Asamblea (artículo 244).

47 Artículo 131 de la Constitución del Perú. El artículo 85 del Reglamento del Congreso sobre preguntas y respuestas.

48 Artículo 134 de la Constitución del Perú, si el Congreso ha censurado o negado la confianza a dos Consejos de Ministros.

49 VALADÉS (1998) p. 366. 
a.- La parlamentarización del hiperpresidencialismo iberoamericano. Los diversos presidencialismos iberoamericanos llevan tiempo parlamentarizándose como un remedio para frenar el hiperpresidencialismo. Esto es un dato normativo fácilmente demostrable. Es una tendencia creciente en las normas constitucionales iberoamericanas, ya muy estudiada, más aún en los Reglamentos parlamentarios y no hará falta que me detenga en ello.

Baste con señalar que en las constituciones de algunos países de la región se acepta la censura o el rechazo de la confianza de los ministros de forma individual o colectiva; o existe un Jefe del Gabinete o Consejo de Ministros distinto del Presidente que es políticamente responsable ante el Congreso; o cabe la disolución de las Cámaras en ciertos supuestos tasados pero de amplio entendimiento ${ }^{50}$; o se admite que los Ministros puedan ser legisladores, o ser interpelados, o recibir solicitudes de datos e informes ${ }^{51}$. Hay casi tantas variantes nacionales como regulaciones.

Ha habido de hecho distintas intensidades o grados deparlamentarización del presidencialismo iberoamericano como ha señalado Nogueira: la adopción del parlamentarismo en períodos de la historia de algunos países, o la organización de un semipresidencialismo ${ }^{52}$, o, mucho más frecuentemente, la introducción de herramientas propias del parlamentarismo, lo que parece ser la tendencia más general.

Tal orientación, limitar el hiperpresidencialismo con herramientas parlamentarias, lleva a la creación de unos sistemas híbridos. Al igual que ha ocurrido en otros escenarios constitucionales del continente latinoamericano con la hibridación de la inicial jurisdicción constitucional "difusa" agregando aditamentos propios de la "concentrada" v.gr. en México o en Perú.

b. - La presidencialización del parlamentarismo europeo. En el otro continente y extremo de la comparación, Europa, existe una tendencia creciente hacia un fuerte liderazgo del Canciller, Presidente o Primer Ministro. Esto ha ocurrido en Alemania, Reino Unido, Italia y España. Especialmente en España donde existe un fuerte principio de liderazgo presidencial $^{53}$, frente a los complementarios principios de colegialidad gubernamental y

50 Cfr Constitución de Ecuador artículo 148 donde el Presidente de la República puede disolver la Asamblea en tres amplios supuestos: si se arroga funciones que constitucionalmente no le corresponden, si obstruye reiteradamente la ejecución del plan nacional de desarrollo, y por graves crisis políticas y conmoción interna. Como contrapartida, también la Asamblea Nacional puede destituir al Presidente por arrogarse funciones que no le competen o por graves crisis políticas (artículo 130). En ambos casos, previo dictamen de la Corte Constitucional.

51 Entre otros muchos, passim Jorge CARpIzo: ob.cit., en especial pp. 200-205.

52 Ver SABSAY (1992) pp. 197-214. SabSAY reconoce que el semipresidencialismo no ha llegado a consolidarse como las otras dos "formas puras" (p. 200). Recuerda que el clásico en la materia, Duverger, identificaba la diferencia principal en la existencia de un Primer Ministro políticamente responsable ante la Asamblea y distinto del Presidente de la República (de ahí la posibilidad de la llamada "cohabitación"), y en la presencia de una relación de colaboración entre Gobierno y Parlamento (pp. 205-206). Algo que existe actualmente en Argentina.

Tanto SABSAY como Humberto NogUeIRA (1988) pp. 125-161, han defendido el semipresidencialismo como un remedio para frenar el hiperpresidencialismo de Iberoamérica, para fomentar la colegialidad del Gobierno, generar consensos y relaciones de colaboración. La existencia del semipresidencialismo como un tertium genus me parece apoya también la tesis del continuum entre presidencialismo y parlamentarismo que en este trabajo se propone. Hay numerosos escalones de parlamentarización/presidencialización, diversas fusiones, casi tantos como de centralización/ descentralización; y es cada vez más difícil hablar de "formas puras" o tipos ideales.

53 Ver BAR (1983). In extenso, VVAA (2005). 
autonomía departamental de los ministerios ${ }^{54} \mathrm{y}$, sobre todo, frente a la perdida centralidad del Parlamento -si alguna vez existió- que languidece en manos de la mayoría. Una preeminencia y jerarquía presidenciales - un todopoderoso líder del Gobierno y de la mayoría parlamentaria- que se han visto robustecidas hasta ahora en España. Pero parecen frenarse en 2015 con el nuevo escenario que entraña lo que podemos llamar un "tetrapartidismo imperfecto”. Así ha ocurrido por la ausencia de Gobiernos de coalición a nivel nacional -solo ha habido pactos de legislatura, a diferencia de en Alemania- merced a un sistema electoral que se llama "proporcional", pero que en la realidad otorga fuertes primas de sobrerrepresentación a los dos primeros partidos; por una menguada responsabilidad política, a causa de la fuerte disciplina de partido que producen las listas electorales cerradas y bloqueadas; y, sobre todo, por la ausencia de una arraigada cultura parlamentaria donde se engaste confortablemente como un hábito la vinculación a la responsabilidad política según ocurre en el Reino Unido y otros países. Todo buen parlamentarismo demanda una cultura repleta de usos y convenciones y al cabo de principios jurídicos y no solo reglas. El modelo europeo es además, en muchos casos, un parlamentarismo racionalizado o fuertemente formalizado, así ocurre en España y en otros países que siguen las pautas de Alemania. Un modelo diseñado en el período de entreguerras, entre otros por MirkineGuetzevitch $^{55}$, pero construido más tarde en la Ley Fundamental de Bonn por reacción a lo que ocurrió en el período de Weimar, y que intenta asegurarse a toda costa de la gobernabilidad. Se asocia estabilidad constitucional con estabilidad gubernamental ${ }^{56} \mathrm{y}$, en consecuencia, se hace muy difícil la exigencia de la responsabilidad ministerial a través de mecanismos de control parlamentario y sanción. Diego Valadés ha advertido que la restrictiva regulación de la moción de censura "constructiva", que demanda la presencia de un candidato alternativo a la presidencia, tiene un "efecto inhibitorio" 57 del parlamentarismo, que de algún modo se presidencializa; y lo mismo podríamos perfectamente decir de otros mecanismos "racionalizados".

"Racionalización”, por cierto, no deja de ser una palabra mágica con efectos taumatúrgi$\cos ^{58}$, tal y como los españoles hemos podidos constatar con diversas leyes así intituladas desde la Gran Recensión que comenzó en 2007. Se incluye racionalización en el título de una ley y el legislador se siente habilitado para hacer cualquier cosa bajo el impulso ilustrado de la razón económica y de la austeridad, prescindiendo de ponderar otros principios no menos constitucionales. Puede pues que no sea tan buena la obsesión por "racionalizar" el parlamentarismo, y que resulte mejor incrementar el debate parlamentario y la responsabilidad política como siempre se hizo. Racionalizar el parlamentarismo ha acabado por devaluarlo, embridarlo y el coste en la función representativa es muy alto.

54 Puede verse García Roca (2005) pp. 153-207, donde se argumenta la jerarquía del Presidente frente a unos Ministros sometidos a sus instrucciones y facultad de cese.

55 Cfr Mirkine-Guetzevitch (1931); y Mirkine-Guetzevitch (1934). La obra de ese autor fue muy conocida en España ya antes de la Guerra Civil y hay dedicatorias de alguno de sus libros a Adolfo Posada en la Complutense. Puede leerse la conferencia de STARCK (2012), pp. 101-119. StarCK mantiene la defensa del modelo.

VALADÉs (1998) p. 269.

Vid Antonio Embid Irujo (2014). 
Un parlamentarismo racionalizado y frenado en algunos países europeos, y, en todos ellos, de fuerte liderazgo presidencial, parece coincidir en su rigidez con un hiperpresidencialismo iberoamericano por más que la separación de poderes sea en el segundo caso mayor. Ya no es tan cierto que, en el parlamentarismo, el motor del sistema sea el Parlamento y no realmente el Gobierno, o directamente el Presidente, que ya no es un mero primus inter pares sino un superior jerárquico ${ }^{59}$. Algunos de los trabajos que comparan ambos sistemas en Iberoamérica y defienden las diferencias mantienen una visión idealizada y obsoleta del parlamentarismo europeo.

c.- Continuidad e influencias reciprocas de los Reglamentos parlamentarios. Existe una fuerte tendencia -en Italia, España e Iberoamérica y probablemente sea universal- de los Reglamentos de las Cámaras a permanecer por debajo de las constituciones, prolongando la validez y aplicación de sus normas, y a recibir influencias recíprocas de los Reglamentos parlamentarios de otros ordenamientos más o menos homogéneos, ya sean parlamentarios o presidenciales. Un rasgo mucho menos destacado al hablar de la fusión de ambos sistemas.

Las bases del parlamento Mexicano y de otros países de Iberoamérica arrancaron en parte de la influencia de la Constitución española de 1812 y de la experiencia de las Cortes de $\mathrm{Cádiz}^{60}$, que diseñaban un sistema parlamentario ciertamente liberal, pero basado en una división de poderes extremadamente rígida -de influencia francesa- y recelosa del ejecutivo que representaba el Monarca. Un recelo que no era de extrañar en ese contexto histórico. Pero esta separación rígida tan doceañista pronto dejó de existir en Europa, para flexibilizarse las relaciones entre Gobierno y Parlamento, y probablemente, de haberse mantenido, no habría podido funcionar. Muchos de estos rasgos permanecen aún en Iberoamérica: la existencia de una Mesa -que no existen en otros modelos europeos- y que en varios países se renueva todavía constantemente; el refrendo ministerial de los actos del Presidente; en ocasiones, la designación de los Ministros o Secretarios sin la intervención del Senado y un largo etcétera... ${ }^{61}$.

Del mismo modo, recordemos que el primer comentario al Reglamento del Senado de los Estados Unidos de América arranca de la influencia parlamentaria del Reino Unido. No podría haber sido de otra manera. Es natural que uno busque fuera y donde mejor conoce soluciones para los problemas que tiene dentro y no sabe como solventar. En efecto, el clásico Jefferson's manual on parliamentary practice ${ }^{62}$, que todavía se reedita, se basa en una colección de precedentes y prácticas del parlamentarismo inglés. Thomas Jefferson lo escribió siendo Vicepresidente de la República y Presidente del Senado de 1797 a 1801. En 1837 la propia Cámara declaró la aplicabilidad de este manual siempre y cuando

Véase García Roca (2005)

60 VALADÉs (1998) p. 337 recuerda que el Constituyente de 1824 llegó a proponer de manera formal que la Constitución de Cádiz de 1812 se adoptara como ley ordinaria en México para integrar supletoriamente las lagunas de la Constitución, siempre que sus normas "no repugnaran a nuestra independencia y libertad".

Vid Jorge CARPIZO: ob. cit., p. 196

62 JefFERSON (1801), 2a edición de 1812 con añadidos del autor, hay una edición especial del Senado en 1993 coincidiendo con 250 aniversario de su nacimiento. Es fácilmente accesible en la red. 
no estuvieran en colisión con the rules and orders of the House. De manera que hubo al principio una cierta continuidad de las prácticas parlamentarias entre Estados Unidos y el Reino Unido por encima de continentes y modelos parlamentarios o presidenciales ${ }^{63}$. Esta misma perspectiva, fundada en considerar términos de comparación homogéneos parlamentarismo y presidencialismo a efectos de controles, sigue un informe publicado por la Unión Interparlamentaria en 2007 sobre "Instrumentos de control parlamentario. Estudio comparativo de 88 parlamentos nacionales" ${ }^{64}$, que incluye información sobre un compendio de prácticas parlamentarias en países como México o Brasil junto a otros como el Reino Unido, Suiza, Canadá o Japón. Si bien no se molesta en justificar esta metodología, y evidencia una cierta despreocupación sistemática que se advierte en un acusado desorden en la exposición de numerosos instrumentos, en simple acumulación o commixtio, algunos de los cuales no suelen identificarse habitualmente como técnicas de control.

Finalmente, el excelente estudio histórico de Fernández Sarasola sobre los Reglamentos parlamentarios españoles demuestra la relativa continuidad de mucha de sus normas y de las prácticas parlamentarias por encima de los frecuentes cambios constitucionales ${ }^{65}$. Parafraseando a un clásico alemán del derecho público, podríamos decir: las Constituciones pasan los Reglamentos parlamentarios quedan.

A la vista de estas tendencias, es perfectamente válida una reflexión con voluntad comparatista sobre el alcance de la función parlamentaria de control en el parlamentarismo europeo y el presidencialismo iberoamericano ${ }^{66}$. Cabe una micro-comparación e influencias recíprocas en materia de controles, aunque ambos modelos no sean cosas idénticas, pero de ahí nace precisamente el interés de toda comparación ${ }^{67}$. Debe eso sí actuarse con prudencia y no con mimetismos ni trasplantes automáticos que rechace la naturaleza del órgano de acogida por la brusquedad del injerto, o las limitaciones al control parlamentario propias del presidencialismo.

Al cabo, los sistemas parlamentarios son fruto de una constante evolución histórica, y no de tipos ideales, y otro tanto cabe decir de los presidencialismos iberoamericanos. Ninguno es mejor que el otro, pero desde luego no son ya compartimentos estancos. El presidencialismo iberoamericano tiene en muchos países tendencias parlamentarias. Eso es un hecho.

63 Ya he recordado que la reflexión comparada entre ambos países y sistemas se mantiene. Cfr MCKAY y JoHsON (2010).

64 Instrumentos de control parlamentario. Estudio comparativo de 88 parlamentos nacionales, redacción y edición de Hironory Yамамото, Unión Interparlamentaria, impreso en Suiza, 2007, es accesible en la red. Hay edición posterior.

65 Vid Fernández Sarasola (2012), con un muy interesante y largo estudio previo.

66 Un autor tan respetado como Jorge CARPIZO: ob.cit., p. 40, rechazaba con razones de peso esta tesis. Defendía que no daba buenos resultados la introducción de controles típicamente parlamentarios en el presidencialismo y hacer un "híbrido". Dada su agudeza, es muy probable que la razón esté de su parte, y siento no poder ya debatir con mi amigo como siempre hice. Pero observo que la región parece moverse en el sentido que reflejo.

Puede leerse García Roca (2014). 


\section{El impacto del sistema de partidos en el presidencialismo. Los peligros del entendimiento absolutista o separatista de la separación de poderes}

En sentido contrario de cuanto precede, es patente que las relaciones entre mayoría y minorias son diversas en el presidencialismo que en el parlamentarismo y que el impacto en ambos del sistema de partidos, a efectos de control, puede ser diferente ${ }^{68}$.

Debemos prevenirnos frente a dos serias amenazas, sendos excesos que conviene desechar y que actúan justamente en sentido contrario. Primero, un entendimiento absoluto y separatista de la separación de poderes presidencial, desprovisto de lógica democrática alguna, que lleve a impedir los controles parlamentarios. Segundo, una excesiva proporcionalidad en la representación, que genere un sistema de partidos y un asamblearismo de las Cámaras que impida la estabilidad del gobierno presidencial ${ }^{69}$.

En el parlamentarismo, un mismo partido o coalición domina por definición ambos órganos constitucionales, de no tratarse de un "parlamento colgado" (hangparliament) ${ }^{70}$ o desaparecer la confianza inicial por causas sobrevenidas, dos supuestos excepcionales respecto de la situación natural. En efecto, la mayoría gubernamental, tras la investidura parlamentaria del presidente y el otorgamiento de la confianza, es necesariamente también mayoría parlamentaria y por ello el interés de la Cámara en controlar al Gobierno que ella misma ha creado corre el riesgo de debilitarse. La mayoría tiende con naturalidad a proteger al Gobierno y a los Ministros contra cualesquiera sanciones, preguntas, informes o posiciones críticas del Parlamento. La protección es más fuerte cuanto más serio sea el escándalo y la amenaza de una petición de responsabilidad política. La literatura británica lleva décadas advirtiendo de este funcionamiento mayoritario del parlamentarismo en la realidad. Así funcionan las cosas desde hace tiempo. Se produce normalmente un control parlamentario extenso o capilar, pero poco intenso y casi siempre desprovisto de sanciones. Esta ha sido la regla general en España. Mucho ruido, pocas nueces... y escasa responsabilidad política.

Por el contrario, en un sistema presidencial, si el Presidente no goza del apoyo de la mayoría de la Cámara, o los apoyos con que cuenta derivados de Gobiernos de coalición o acuerdos de legislatura son inestables y los Grupos mantienen constantes disensos, el control del Parlamento al Presidente puede ser muy intenso. Puede incluso transformarse en serias obstrucciones y bloqueos ${ }^{71}$ a la acción de gobierno presidencial hasta correrse el riesgo de llegar a detenerla en un impasse.

La posterior acomodación de las posiciones, como la ingenua e ilustrada "esperanza de Madison” pretendía, puede no ser sencilla. El presidencialismo iberoamericano -advierte

\footnotetext{
Entre otros muchos, Carpizo (2000) p. 16 y ss, en especial pp. 13-18.

Recordemos que en Italia durante la llamada I República, de 1945 a 1996, los Gobiernos duraron una media de menos de año y medio. Resulta revelador hasta en el título, Amato (1991).

Cfr Alberto López Basaguren (2015)

Vid Nogueira (1988) p. 154.
} 
Gargarella- tiende a "desalentar" las posibilidades de cooperación y de acuerdos, porque la oposición no puede erigirse en Gobierno dada la rigidez del término presidencial ${ }^{72}$. Este bloqueo ocurre con alguna frecuencia en Estados Unidos según hemos presenciado con el llamado fiscal cliffo abismo financiero.

Me temo que con todo este escenario se advierte bien que el presidencialismo liberal - cauteloso de la democracia- diseñado por los padres fundadores estadounidenses en el siglo XVIII no podía prever el posterior impacto del sistema de partidos. Puede que el presidencialismo iberoamericano pague aún los intereses y costes de esa hipoteca. Un sistema de gobierno, el estadounidense, donde es manifiesto que no basta con la mayoría presidencial sino que debe ser refrendada con mayorías posteriores en las dos Cámaras. Sortear este doble freno y alcanzar una triple confianza se revela casi imposible para cualquier mayoría y dificulta sobremanera la acción de gobierno.

Quizás este modelo presidencial estadounidense, tan rígido en su separación de poderes y frenado, no debiera ser mantenido en la evolución del presidencialismo en Iberoamérica, y fuera conveniente efectuar modificaciones en algún caso tendentes a que no sean tan dispares las tres mayorías entre las dos Cámaras y el Presidente. Bastaría con que las elecciones del Presidente y la Cámara baja del Parlamento fueran contemporáneas -ya ocurre así en varios países de la región- o próximas en el tiempo para favorecer el Gobierno de la mayoría. ¿Cuántas elecciones generales debe una mayoría ganar durante un lustro para poder gobernar?

Conviene traer a colación que el propio Bruce Ackerman considera no exportable el presidencialismo estadounidense: el estilo norteamericano de separación de poderes ${ }^{73}$. Una

72 Gargarella (1992) p. 93, advierte que la actitud más racional que queda a la oposición es "obstaculizar los programas de acción del oficialismo". El medio más sencillo para llegar al Gobierno, porque cualquier éxito del liderazgo presidencial disminuye sus oportunidades de sustituirle y alcanzar el poder. La única alternativa es la cooperación en un marco contramayoritario, pero -advierte- solo se produce si la paridad de las fuerzas es notable, o surge una emergencia o grave situación de crisis en la que el acuerdo resulte indispensable para la subsistencia del sistema. Por otro lado, este presidencialismo iberoamericano favorece el corporativismo de los políticos y la captación por el Presidente de dirigentes opositores (p. 104); lo que coadyuva a la concentración del poder.

73 Vid el extenso y excelente artículo -casi una monografía- de ACKERMANn (2000) pp. 633-725. Critica el "triunfalismo" de Steven G. CALABresi en una interesante controversia. Ackerman recuerda que EEUU, muy poderoso tras la victoria en la II Guerra Mundial, no quiso imponer su modelo rígido y excepcional de separación de poderes en Japón y optó por un parlamentarismo constreñido, y un bicameralismo asimétrico: "a one-and-a- halfHouse solution" (p. 635); y que lo mismo ocurrió en Alemania y en Italia (p. 636), pese a las peculiaridades del bicameralismo simétrico italiano que la presidencia de Renzi trata de reformar.

Véase, en sentido contrario, Calabresi (1998), p. 22 y ss. Más tarde Calabresi y Bady (2010) pp. 5-16. CalaBRESI me parece que ofrece argumentos de menor fuerza. Cree, por el contrario, que el modelo estadounidense es exportable incluso a la forma de gobierno de la Unión Europea para superar su déficit democrático; y sugiere que esta exportación es deseable si se cumplen ciertas condiciones p.ej. si el país no ha sufrido una historia de dictaduras o está polarizado en dos bandos. Recomiendan asimismo un bipartidismo y un sistema electoral mayoritario. A mi entender no hay visos algunos de erigir un sistema presidencial en la Unión Europea por la misma complejidad de las dobles legitimidades que la gobierna y las muy diversas posiciones de los Estados y opiniones públicas. Por la misma razón, la complejidad de las sociedades Iberoamericanas no es fácil introducir sistemas mayoritarios donde esta tradición anglosajona no existe. Por lo demás, ha sido larga la historia de pronunciamientos militares y dictaduras en otras décadas. 
experiencia que califica como excepcional ${ }^{74}$. Este autor estadounidense asevera -con provocación y rotundidad- que no puede servir como modelo en otros países. Llega a afirmar que no debería reproducirse una segunda vuelta de "la desastrosa experiencia Latinoamericana del siglo XIX siguiendo el modelo estadounidense" 75 . Se decanta por sugerir que se adopte un "parlamentarismo restringido", controlado o limitado (constrained parlamentarism), y asimétrico (one and-a-halfhouse solution), al modo de Alemania, Italia, España, Canadá, Japón, Sudáfrica, India y otros muchos países. Este modelo moderno y creciente - afirma- trata de controlar el poder del Gobierno por el Parlamento y, a su vez, el poder de ambos por otros órganos independientes como son los tribunales constitucionales. Un modelo de controles institucionales y de parlamentarismo restringido -concluye- ofrece "a more promisingpath to constitutional development than the American approach”. Pues permite garantizar mejor la democracia, la profesionalidad y la protección de los derechos fundamentales, precisamente los tres grandes principios que motivaron en su día la doctrina de la separación de poderes ${ }^{76}$.

Ackerman nos recuerda la conocida experiencia del semipresidencialismo de la República de Weimar donde la Constitución de 1919 diseñó un Presidente elegido directamente y prácticamente libre de controles parlamentarios. Una solución que se reveló como un gran error después de que Hindenburg eligiera como canciller a Hitler ${ }^{77}$.

Unas consideraciones críticas semejantes se han hecho sobre el modelo de doble confianza de la Constitución de 1931 de la II República española a la vista de la experiencia de sus dos presidencias; un sistema del cual la Constitución de 1978 trató de escapar.

Sea como fuere, el camino del constitucionalismo occidental -comparto la reflexión de Ackerman- tanto en el presidencialismo como en el parlamentarismo debería consistir en asegurarse de un sistema de controles, internos y externos y de muy diverso tipo, que embriden el poder y garanticen los derechos fundamentales y el federalismo donde sea necesario. No se trata de mantener una separación de poderes absoluta y rígida hasta el punto de impedir razonables pesos y contrapesos, porque no se advierte que otros bienes y valores constitucionales preserva esta alternativa. "Separations of power on behalf of what?", se pregunta Ackerman, y concluye que con la tentación del separatismo corremos el riesgo de erigir el ejecutivo en un enemigo del Estado de Derecho ${ }^{78}$.

74 Juan J.LINZ coincide con ACKERMAN en esa excepcionalidad del presidencialismo de EEUU, así como en la defensa del parlamentarismo. Entre otros trabajos, "Los peligros del presidencialismo" en Liz, NoHLEN y otros (1993) p. 27.

En sentido contrario, una defensa argumentada del enfoque tradicional, frente a las críticas doctrinales al presidencialismo: no hay una mejor forma de gobierno con carácter universal, la experiencias empíricas no demuestran la superioridad del parlamentarismo, hay pocas expectativas para que América Latina cambie al parlamentarismo, no existen experiencias de parlamentarismo en la región que comparar, no hay un tipo homogéneo de presidencialismo, etc.; puede leerse la obra colectiva dirigida por dos politólogos estadounidenses MAINWARING y SOBERG SHUGART (1997). Pero el análisis de los dos editores me parece muy descriptivo y no creo permita extraer principios generales. Vid su aportación "Presidentialism and democracy in Latin America: rethinking the terms of a debate" en ob.cit., pp. 12-54.

Ackermann (2000) p. 725.

Idem, p. 634.

Idem, p. 636

Idem, p. 639. 
Del mismo modo, carece ya de sentido un modelo Westminster fundado en la soberanía del Parlamento, desprovisto de controles -otra versión del separatismo-, entre otras muchas razones, porque el control de constitucionalidad-convencionalidad que entraña el Tribunal Europeo de Derechos ha erosionado seriamente ese dogma, y otro tanto semejante ocurre con la Corte Interamericana. Por otro lado y desde la lógica interna, ningún órgano constitucional puede ser titular de toda la soberanía por definición. La idea de soberanía del parlamento es tan vieja y obsoleta como la exacerbación del poder presidencial.

La rigidez y el absolutismo en la separación de poderes, en definitiva, no funcionan y es menester asegurarse de la existencia de controles que impidan presidencialismos desbordados y autoritarios. Los hiperpresidencialismos ${ }^{79}$ son en parte consecuencia de una exégesis separatista de aquel principio desprovista de un fundamento axiológico. Cualquier organización constitucional se funda en la colaboración de órganos y entes territoriales y en la existencia de controles y no en un choque de legitimidades separadas.

Por otra parte, conviene distinguir la situación del presidencialismo conforme a dos tipos de sistemas de partidos con diferentes incidencias en la función de control. Primero, un presidencialismo ligado al bipartidismo como consecuencia de un sistema electoral mayoritario: el modelo estadounidense clásico. Parece resultar un diseño más estable de relaciones, aunque depende de la lealtad o disciplina de los parlamentarios respecto de sus partidos.

Segundo, diversos presidencialismos iberoamericanos en los que ha acabado por imponerse la representación proporcional y existe un pluripartidismo más o menos polarizado o extremado ${ }^{80}$. La estabilidad de estas relaciones entre órganos deviene entonces más problemática y las soluciones más complejas. Al cabo compaginar presidencialismo y la previsión constitucional de gobiernos de coalición, como ocurre ya en México tras la reforma constitucional de $2014^{81}$, hubiera sido difícilmente imaginable hace décadas, pues se trata de una herramienta típicamente parlamentaria en su origen. No menos atípico es el presidencialismo de Argentina con un ejecutivo dual y responsabilidad política ante el Congreso del Jefe del Gobierno.

Claramente, el riesgo de una obstrucción o impasse se intensifica con la unión de presidencialismo y pluripartidismo. Una pluralidad de partidos - más de cinco o seis- que no

79 Ackermann (2000) p. 645 lo califica como "la pesadilla de Linz", caudillos-presidentes que se deshacen en las Repúblicas latinoamericanas de parlamentos intransigentes con la ayuda de los militares o de poderes al margen de las constituciones. Advierte con brillantez que tiene que haber un camino entre la esperanza de Madison y la pesadilla de Linz.

80 ACKermann (2000) afirma (ob.cit. p. 655) que, si alguien está atraído por la superior legitimidad democrática que entraña la representación proporcional, entonces ha encontrado otra razón para rechazar el presidencialismo y la separación de poderes al estilo estadounidense.

81 Véase BARCELó y VALAdÉs (2016). En el estudio previo al anteproyecto se justifica la reforma por la multiplicidad de partidos políticos y se resalta que los gobiernos de coalición son una constante también en el presidencialismo mediante el nombramiento de un Gobierno plural de altos funcionarios. Una evolución natural de la democracia presidencial, pero que debe someterse a controles. El informe defiende la vigencia del pluripartidismo como la mejor representación posible de la sociedad civil. 
pueden convertirse en mayoría gubernamental y derribar el Gobierno -como ocurriría en el parlamentarismo-, puede bloquear todas las iniciativas presidenciales, exagerando o desproporcionando el control ${ }^{82}$. Una muestra de minorías negativas que impiden el funcionamiento del sistema sin poder erigirse en alternativa ante el tiempo cerrado del mandato presidencial.

Representación proporcional y pluripartidismo son pues una aventura y desafío en Iberoamerica respecto del original modelo presidencialista y de separación rígida de poderes. El diseño liberal y presidencial de los padres fundadores estadounidenses fue pensado ignorando la moderna idea de sistema de partidos y de competición entre esas fuerzas, de hecho, desconfiaban de los partidos como facciones, y poseían una filosofía política "wary of democracy" ${ }^{33}$. Las interrelaciones entre pluripartidismo y presidencialismo, de un lado, limitan el hiperpresidencialismo y conducen a algún grado de parlamentarización, a la introducción de técnicas parlamentarias de control; y, de otro, coadyuvan a un cierto abandono del viejo entendimiento separatista o absolutista de la separación de poderes.

La ruptura de la ecuación bipartidismo-presidencialismo transforma la forma originaria de gobierno en Iberoamérica, pero no sé si llega a ser una mutación. En todo caso, no creo pueda mantenerse un coctel explosivo de ingredientes: presidencialismo, representación proporcional, multipartidismo extremado, y un entendimiento absolutista de una separación de poderes rígida que impida los controles parlamentarios ${ }^{84}$.

La reducción más sencilla de esa tremenda complejidad consiste en flexibilizar la separación de poderes rígida hasta donde se pueda en un modelo presidencial basado en una lógica personalista e introducir serios controles de las Cámaras ${ }^{85}$. También el parlamentarismo europeo de Presidente conlleva un fuerte liderazgo presidencial, pero no excluye los controles parlamentarios, usando la separación de poderes como una patente de inmunidad ni lleva a una peligrosa politización de una administración profesionalizada ${ }^{86}$.

\footnotetext{
Vid Ackermann (2000) p. 656

En este sentido, ACKermann (2005), epígrafe “The original misunderstanding” p. 16 y ss, la cita en p. 18.

4 ACKermann (2000) p. 656. Coincido con sus afirmaciones sobre el presidencialismo que proyecto a Iberoamérica. Me parece que mientras la representación proporcional es deseable en Iberoamérica por el intenso pluralismo de muchas de sus sociedades (lingüístico, étnico, cultural, fuertes niveles de pobreza y desigualdades económicas...), el entendimiento absoluto y separatista de la separación de poderes, excesivamente personalista, no lo es y no debería mantenerse.

85 Por el contrario, CALABRESI y BADY (2010) p. 5, censuran la adopción de la representación proporcional en Iberoamérica. Una tesis que rechazo: pretender que sociedades tan complejas como las iberoamericanas, con claves como la pobreza y las comunidades indígenas o la extensión territorial, pueden reconducir su representación y simplificar su complejidad en torno a sólo dos grandes opciones bipartidistas no es real ni deseable.

86 Ackermann (2000) pp. 699 y ss asocia el entendimiento separatista de la separación de poderes con el gran poder de una alta burocracia desprovista de controles. Unas formas poco atractivas de "bureaucratic governance" donde es difícil distinguir el rol de una Administración de servidores públicos, políticamente neutrales, de las funciones políticas encargadas a los representantes. Una politización de la burocracia que califica de "aberración" al permitir al Presidente colonizar la burocracia con funcionarios-políticos leales. A diferencia de una más clara distinción en Europa, aunque el riesgo asimismo exista, pero la presencia de una especializada jurisdicción contencioso-administrativa en muchos países incrementa los controles judiciales frente a ilegalidades y arbitrariedades.
} 


\section{Instrumentos de control}

1. ¿Es indefectible una previsión constitucional, su expresa atribución a las Cámaras, para ejercer la función de control? ¿También una regulación sistemática y separada de dichos instrumentos en los Reglamentos de las Cámaras? Ni una y otra cosa son imprescindibles, aunque sean convenientes. La función de control del Gobierno es inherente a todo Parlamento, por encima de las formas de separación de poderes, pues se deduce de las ideas de responsabilidad y representación política. Por otro lado, la técnica defectuosa de los Reglamentos parlamentarios, incluso su obsolescencia, no debe conducir a restringir necesariamente al ejercicio de los instrumentos allí previstos; si bien en la realidad tiende a hacerlo, porque la mayoría que no se preocupa de codificar y mantener actualizado un buen Reglamento que permita los debates, no suele tampoco tener la voluntad de permitir ser controlada. Pero qué duda cabe de que es deseable la atribución expresa al Parlamento en la Constitución de la función de fiscalización del Gobierno, al modo de un recordatorio y mandato. Tan deseable como que un moderno Reglamento parlamentario codifique con voluntad sistemática algunas experiencias propias y de otros países que se estimen buenas prácticas de control.

Cabe pensar que ocupándonos de una norma atributiva de competencia a la Asamblea su naturaleza debe ser expresa y no implícita, en buena técnica hermenéutica, pero este argumento olvida que la función de control puede reconducirse a concretas atribuciones de instrumentos que sí vengan previstas. De hecho la construcción de la función es doctrinal y posterior al uso de las herramientas. La ausencia de una norma expresa no es un obstáculo insalvable.

El texto de la más antigua Constitución italiana en 1947 no mencionaba expresamente la función de control. A diferencia de como hace el más moderno artículo 66.2 de la Constitución española de 1978. Una y otra son muestras de reconocimiento tácito e implícito y de previsión expresa. Recientemente, la Ley constitucional $n^{\circ} 1$ de 2012, de 20 de abril, que desarrolló el principio de equilibrio presupuestario en la Constitución italiana, atribuyó la función de control a ambas Cámaras, si bien circunscrita a la función financiera y presupuestaria. Mas esto no quiere decir que no se deba proyectar sobre el resto de la función, en todo caso, esta reforma constitucional explicita la tendencia a incluir la función de control en normas constitucionales.

Los Reglamentos parlamentarios de bastantes países han desarrollado de forma conjunta los instrumentos de control según parece conveniente. En España, el Reglamento del Congreso de los Diputados no dedica un único Título al control, pero aborda con continuidad y de forma seguida las diversas variantes de control tras disciplinar el procedimiento legislativo. En cambio, en Italia, el Reglamento de la Cámara de los Diputados en su Parte III regula en un mismo Título los procedimientos de "dirección política, control" e información con bastante exhaustividad. 
En Iberoamérica, la Constitución de Bolivia reconoce la función fiscalizadora de las comisiones y el control de otros órganos competentes (artículo 158.I.19), la de Ecuador dedica la sección $2^{\text {a }}$ del Capítulo segundo del Título IV (artículos 129 a 131) al control de la acción del Gobierno, y la de Venezuela el artículo $222^{87}$. La Constitución de Chile atribuye a la Cámara de los Diputados la facultad de "fiscalizar los actos del Gobierno" (artículo 52.1) y, a continuación, enuncia con detalle varios instrumentos de control. Asimismo el Reglamento de la Cámara de los Diputados de ese país, con buena voluntad sistemática, dedica el Libro Tercero a la información, fiscalización y otros mecanismos de control. También el Reglamento del Congreso de Perú regula de forma unitaria y sistemática (Capítulo VI, sección $2^{\mathrm{a}}$ ) el "procedimiento de control político" (artículos 82 a 92).

En cambio, el Reglamento de la Cámara de los Diputados de la República Dominicana si bien afirma en su exposición de motivos que la función de fiscalización está ligada al principio representativo, se refiere luego a la función de fiscalización de las comisiones y la obligación de los funcionarios de suministrar informes y documentación (artículos 131 y ss), así como recoge algunas herramientas de control, sin embargo, no efectúa un tratamiento sistemático y unitario de la función de control como me parece aconsejable por razones de unidad temática y tratamiento exhaustivo. No obstante, la propia Constitución dominicana (artículo 93.2) reconoce atribuciones al Congreso Nacional en materia de fiscalización y control, y regula separadamente instrumentos como son comparecencias o invitaciones a las Cámaras, solicitudes de información e interpelaciones. Acaso todo ello pudo servir de apoyo para un desarrollo más sistemático en el mencionado Reglamento.

No obstante, de todas estas diferencias en las normas, en las que no podemos detenernos, puede que no se desprendan en la práctica diferencias tan relevantes, aunque los matices sean esenciales en Derecho.

2. Existe una larga convención comparada, muy extendida, por la cual reconducimos a la función de control toda una serie de instrumentos que pueden usarse, según los casos, ya sea en Pleno o en comisiones o en ambos a la vez, en la Cámara baja o en la alta o solo en la primera o solo en la segunda. Es una distinción por preferencia, porque algunas de estas herramientas inciden en varias funciones y prima la faceta del control en ellas.

Mencionaré algunas de estas prácticas bien conocidas:

- preguntas, con respuesta oral o escrita, sobre cuestiones concretas, e interpelaciones sobre políticas generales que suelen abrir un debate más amplio y permiten concluir con la aprobación de una moción, ambas variantes del derecho a la inte-

\footnotetext{
El artículo 222 de la Constitución de Venezuela reconoce, como instrumentos de la función de control parlamentario, preguntas, interpelaciones, investigaciones, autorizaciones y aprobaciones parlamentarias y reenvía al Reglamento parlamentario para prever "cualquier otro mecanismo"; y permite a la Asamblea declarar la responsabilidad política de los funcionarios públicos en el ejercicio de esta función.
} 
rrogación y de confusa distinción en la práctica; suelen ser de menor periodicidad en el presidencialismo o venir limitadas en su frecuencia;

- comparecencias ministeriales, exposiciones a cargo de los miembros del ejecutivo sobre el estado del gobierno, o de otras autoridades, o incluso de ciertos funcionarios superiores responsables de esferas de decisión, o de directivos de empresas públicas o agencias independientes;

- comparecencias, consultas y audiencias a solicitud de las comisiones, pueden servir no solo para escuchar al Gobierno sino también a expertos o a miembros de la sociedad civil, fomentando la participación ciudadana;

- comisiones parlamentarias de investigación creadas ad hoc y dotadas de algunas facultades para esclarecer ciertos hechos de importancia política y, en realidad, para transferir información a la opinión pública; serán previsiblemente parcas en su creación y más magras aún en su eficiencia, si la iniciativa de su erección y su funcionamiento no se deja en manos de las minorías;

- solicitudes de informacióny documentación bien a instancias de los parlamentarios o de los Grupos o bancadas; son controvertidos los límites a estas solicitudes derivadas del obstruccionismo de las minorías, o de la tutela de derechos fundamentales de terceros u otros bienes constitucionales por el Gobierno a la hora de formular sus respuestas;

- mociones de censura o de reprobación de los ministros por la gestión de sus competencias (responsabilidad individual frente a la solidaria) mediante distintas fórmulas, ya estén expresamente previstas en normas constitucionales o en los Reglamentos parlamentarios, o generadas espontáneamente mediante usos y costumbres;

- acusaciones constitucionales del Presidente de la República, los Ministros y otras autoridades por graves infracciones de la Constitución y las leyes;

- proposiciones no de ley o mociones de impulso en las que las Cámaras manifiestan al Gobierno su posición y seleccionan fines en la dirección política, participando en la acción de gobierno;

- intervenciones inaugurales del período ordinario de sesiones o informes por el Presidente, seguidos o no de un debate;

- controles financieros como son la aprobación de la Ley de Ingresos y del Presupuesto de Egresos, la revisión de la cuenta pública nacional, o las bases para celebrar empréstitos o la deuda nacional;

- controles sobre nombramientos presidenciales que deben ser ratificados por el Senado; y la tradicional autorización para viajar al extranjero al Presidente de la República; 
- informes de órganos auxiliares del parlamento, independientes en el ejercicio de sus funciones (defensores del pueblo ${ }^{88}$, contralorías ${ }^{89}$ o tribunales de cuenta u órganos externos de fiscalización, consejos de radiodifusión...), que coadyuvan a la labor parlamentaria de control en cuestiones específicas, y cuya presentación suele abrir un debate e impulsar la toma de decisiones;

- comisiones mixtas o bicamerales de relación con órganos o entes;

- y, en definitiva, un largo etcétera de procedimientos incluso controles intraprocedimentales ${ }^{90}$, internos a los procedimientos parlamentarios, mucho menos estudiados, como pueden ser el Comité para Legislación, o algunas labores de la Comisión de Presupuestos y la Oficina Presupuestaria, que son materialmente controles del Gobierno.

El análisis de la idoneidad, eficacia y oportunidad, de cada uno de estos instrumentos de control-responsabilidad política o control-fiscalización requeriría de todo un tratado. Subrayaré simplemente algunas consideraciones generales, y, más adelante, las aplicaré a algunos ejemplos problemáticos de control en el presidencialismo mexicano.

3. Todos estos controles forman un sistema, responden a fines complementarios, y puede que no todos ellos sean necesarios a la vez, y que, por el contrario, resulte conveniente seleccionar y fortalecer unos frente a otros, de acuerdo con las diversas realidades y experiencias de cada país. No existe más control por simplemente acumular herramientas, que es la solución más sencilla, pero no la más eficiente.

El poder es por naturaleza "dinámico" y tiende a desbordarse, y sus malas prácticas se transforman de tiempo en tiempo, de manera que la regulación de estas herramientas no puede ser "estática" ". Las normas de procedimiento que regulan los instrumentos de control deben ser permanentemente actualizadas en los Reglamentos parlamentarios, para impedir que queden obsoletos o vengan decodificados en provecho de la potestad reglamentaria de los órganos de dirección.

Si bien esta transformación puede igualmente producirse en usos y costumbres parlamentarias, una forma espontánea de creación del Derecho, muy típica de una corporación como son las Cámaras y que se demuestra harto más flexible”. En España, la reprobación individual de los Ministros no viene prevista en la Constitución ni en los Reglamentos del Congreso y Senado, pero estas iniciativas se tramitan y recopilan en la web del Congreso, reflejando un uso parlamentario muy consolidado; también en Italia y Alemania tuvieron una génesis espontánea ${ }^{92}$.

Así el artículo 86 de la Constitución de Argentina prevé el Defensor del Pueblo como órgano de control del ejercicio de funciones administrativas públicas.

89 Cfra artículos 213 a 217 Constitución de Bolivia dentro de un Título $V$ sobre la función de control y otros extremos. El artículo 85 de la Constitución de Argentina sobre la Auditoría General de la Nación como órgano de control externo y asistencia técnica del Congreso

Vid García Roca y Ibrido (2013)

En este sentido, VALADÉs (1998) p. 12.

Puede leerse García Roca (2005). 
La lamentable experiencia de la comisión parlamentaria de investigación del caso Banesto y la actuación del Sr Mario Conde, quien luego sería condenado criminalmente, pero se dirigía a los parlamentarios displicentemente o con altivez desde la Mesa, llevó a cambiar la situación de los comparecientes, bajándoles del estrado y modificando la escenografía de las comisiones, para que quedara claro quien está siendo investigado y respondiendo de actos presuntamente irregulares. La negativa a comparecer en las comisiones de investigación tuvo que ser tipificada como delito para asegurarse de la autoridad del Parlamento, y un largo etcétera de asuntos. Basten estas muestras de dinamismo y trasformaciones.

También la regulación de los controles debe aprovechar las oportunidades que ofrecen los nuevos medios tecnológicos - que ya no son nuevos sino fácilmente disponibles-, para facilitar algunas cuestiones. Como puede ser la presentación de preguntas urgentes; $\mathrm{O}$ las relaciones de los ciudadanos con sus parlamentarios, permitiendo que les sugieran preguntas, solicitudes de información o enmiendas, o recibir información especializada mediante listas de correo; o la adecuada información institucional a los ciudadanos de la actividad de las Cámaras en sus respectivas webs; o la muy deseable aplicación parlamentaria del principio de transparencia mediante medios informáticos.

Por último, pero no en importancia, si en virtud del principio presidencial, que pospone o difiere la responsabilidad política al término del mandato, haciendo controlador de la misma al electorado y no al Parlamento ${ }^{93}$, no se desea trasladar mecanismos de control-responsabilidad política (censura, remoción de ministros...) a Iberoamérica, muy probablemente podría bastar con reforzar e implementar con eficiencia otro tipo de controles más cotidianos y ordinarios del ejecutivo ${ }^{94}$. Son harto habituales en la región ${ }^{95}$ los instrumentos que solemos llamar control-fiscalización o información ${ }^{96}$. Reforzar y consolidar estos instrumentos en el presidencialismo iberoamericano,

93 Algunos creen que este sistema presidencial, de "direct accountability" supone a "superior electoral accountablity" y que basta con la posibilidad de la no reelección del Presidente por los votantes. Esta es -a su juicio- una seria ventaja del presidencialismo. Vid MAINWARING y SOBERG SHUGART (1997). pp. 33-36, donde se aporta un detallado estudio de las facultades presidenciales. Recordemos, en sentido contrario, que RoussEAu ya advirtió magistralmente de que los ingleses se creen libres porque votan una vez cada cuatro años.

94 Nogueira (1988) p. 161) parecía confiar preferentemente -pero hace más de dos décadas- en introducir técnicas de responsabilidad política en Iberoamérica para limitar el presidencialismo como p.ej. la moción de censura constructiva alemana y española. Sin embargo, veo difícilmente incompatible control-responsabilidad política con presidencialismo, por la rigidez del mandato. Además la censura constructiva la experiencia ha revelado que casi nunca prospera y no funciona como exigencia de responsabilidad ni en Alemania ni en España. Concluyo que quizás debemos concentrarnos en el control-fiscalización según propongo.

95 Por ejemplo el extenso Título II del Reglamento de la Cámara de Diputados de Chile sobre la fiscalización de los actos del Gobierno; su artículo 295 prescribe que la Cámara puede adoptar acuerdos o sugerir observaciones sobre los actos del Gobierno, siempre que lo decidan la mayoría de los Diputados presentes; el artículo 298 establece que las comisiones de investigación pueden citar a los Ministros; los artículos 303 quarter y ss regulan con detalle las preguntas parlamentarias.

96 También Nestor Pedro SAGÜÉS estima que el enorme poder del Presidente -su legitimidad democrática personal-, casi un César republicano, demanda un correlativo incremento del control, y nadie mejor que el Congreso por su carácter representativo para desempeñar ese poder. Vid "Formas de gobierno. Aproximaciones a una teoría del control parlamentario sobre el poder ejecutivo" en Liz, NoHLEN y otros (1993) p. 91. Este control -afirma en p. 92 y ss- puede hacerse en tres subfunciones: en la elección del Gobierno (subfunción electoral), en lo que llama subfunción cognoscitiva e inspectiva -interpelaciones, solicitudes de información, comisiones de investigación...-, y 
para mantener informadas a la minoría y a la opinión pública, puede ser una vía para perfeccionar la democracia representativa y limitar los excesos ${ }^{97}$. Al cabo, tampoco la responsabilidad política ligada a la censura y al cese funciona tan bien en buena parte de los parlamentarismos europeos.

La función del Derecho Constitucional, tanto en el presidencialismo como en el parlamentarismo y en cualquier fórmula de división de poderes, no es otra que controlar al Principe: fiscalizar al poder. El gobierno constitucional es un gobierno moderado y representativo desde sus orígenes liberales en ambos hemisferios (Madison, Hume, Locke, Montesquieu...). Este razonamiento no se altera aunque los mandatarios y gobernantes sean fruto de una mayoritaria elección democrática. Un axioma que quizás algunos de los llamados "nuevos constitucionalismos" o constitucionalismos del sur o transformadores y diversos populismos ${ }^{98}$ no advierten con suficiente propiedad. Sin controles, la democracia constitucional no existe; no basta con la regla de la mayoría. El control parlamentario y la responsabilidad política son centrales, junto a los principios de independencia judicial y separación de poderes en un esquema de gobierno democrático, incluso frente a las emanaciones o esquejes del poder constituyente, que no puede actuar cotidianamente realizando funciones ejecutivas -como un poder constituido- sin violar aquellos principios. Hay una división de poderes entre poder constituyente y poderes constituidos y sus funciones no deben mezclarse.

4. Reseñemos ahora algunos ejemplos, sin afán alguno de exhaustividad sino de utilizarlos como banco de pruebas de la metodología propuesta. Se trata no de solventar los problemas sino más modestamente de advertir la necesidad de mantener la lógica de esta función parlamentaria de control a la hora de debatir sobre las regulaciones y aplicaciones más adecuadas.

Es clásica en México la controversia sobre el formato del informe presidencial 99 . La Constitución (artículo 69 en su versión original de 1917, varias veces modificada) establecía que a la apertura ordinaria de sesiones, ordinaria o extraordinaria, del Congreso asistirá el Presidente de la República y presentará un informe por escrito; en el primer caso, sobre el estado general que guarda la administración pública del país;

en una serie de autorizaciones (subfunción integrativa). Pide asimismo revitalizar en el presidencialismo y ampliar los instrumentos de control parlamentario Mora-DonatTo (2001) pp. 85-113, en la línea que este artículo propone. Me decanto -con realismo- por reconducir el control en el hiperpresidencialismo iberoamericano a lo que en España e Italia se ha consolidado como control-fiscalización con preferencia sobre el control-responsabilidad politica.

97 Nestor Pedro SAGÜÉs: ob.cit., pp. 95 y ss se refería en 1993 a la "progresiva decadencia" del control parlamentario en la región. Puede que la situación haya mejorado algo. Pero es verdad que superar esa decadencia reclama todavía corregir varios defectos que ya entonces denunciaba: Cámaras con buenos medios técnicos, organizativos y personales, unos servicios profesiones de los Parlamentos mejor formados frente a la burocracia presidencial; la colaboración del ejecutivo, un cambio del paradigma cultural; la tenacidad -casi tozudez- de los parlamentarios e independencia respecto del Presidente frente a un sistema de lealtades personales; y no dejar el control en manos del partido de la mayoría, poco animando a inspeccionar a su propio Presidente.

98 Es conveniente leer, dados los actuales contextos populistas en Iberoamérica y España, LACLAU (2005), sobre una teoría emotiva de "las masas" y su psicología, abandonando su tradicional descalificación como algo patológico. Se sostiene que la racionalidad pertenece al individuo y que la pierde cuando participa en "la multitud".

99 Entre otros, VALADÉs (1998) p. 379 y ss. Quien vuelve a señalar la influencia de la tradición que emana de la Constitución de Cádiz, y se muestra asimismo favorable a facilitar las relaciones entre Cámara y Presidencia. 
y en el segundo, para exponer las razones que hicieron necesaria su convocación ${ }^{100}$. Una técnica con origen tanto en la Constitución de los Estados Unidos (artículo II, sección 3), que no dispone trámites de procedimiento y simplemente permite al Presidente dar "información del estado de la Unión" al Congreso "de tiempo en tiempo", como en la Constitución de Cádiz.

Se admite generalmente que el informe presidencial mexicano representa un ejercicio de rendición de cuentas al pueblo, pero hasta ahora no había llegado a configurarse como una modalidad de control-información del Parlamento. Una larga polémica se ha mantenido ${ }^{101}$ acerca de si la lectura del informe escrito debería abrir un debate parlamentario, y aceptarse preguntas o interpelaciones de diputados y senadores; $\mathrm{o}$, por el contrario, se trata de un trámite formal y solemne - se ha tachado de ceremonia faraónica-, meramente protocolario tanto en la llegada como en la salida del Presidente, que no viene obligado a responder, por más que los parlamentarios tiendan en la práctica a interrumpirlo con frecuencia y se resistan a escuchar como meros convidados de piedra. Algunos defienden que la inclusión de un trámite parlamentario violentaría la separación de poderes presidencial, pues se trata originariamente de un intercambio entre el Presidente y el pueblo y no con las Cámaras, siguiendo la tradición de los Estados Unidos. Pero muchos entienden que difícilmente en un sistema representativo el primer representante de la nación puede no dar respuestas a los demás representantes del pueblo ${ }^{102}$ y que la ordenación del procedimiento debería transformarse.

Este segundo razonamiento me parece sólido y me hace pensar que algún mecanismo de relación entre órganos debería regularse, entre otras razones, para no ningunear a la opinión pública. Porque el pueblo en realidad no puede dialogar con el Presidente si no es a través de sus representantes ni siquiera votar en ese momento ni hasta la próxima elección presidencial; y porque cualquier procedimiento parlamentario supone por definición oralidad, publicidad y discusión. Todo ello frente al viejo discurso británico y español ${ }^{103}$ del Trono o la Corona del que emanó este instrumento presidencial, respectivamente, en Estados Unidos y en México, pero que no puede tomarse ya como modelo en el siglo XXI. En esto como en tantas otras cosas

100 También la Constitución de la República Dominicana establece (artículos 91 y 114) la rendición de cuenta anual de los Presidentes por las actividades legislativas, administrativas y financieras realizadas, debiendo acompañar un "mensaje explicativo". Asimismo para los legisladores (artículo 92).

101 Vid Chavez (2002) pp. 817-857, donde se da noticia de una veintena de propuestas de reformas de ese artículo 69 de la Constitución nada menos que desde 1917. El autor se preguntaba si la rendición de cuentas que el trámite entraña no debería tener la naturaleza de una forma de control y sintetizaba las propuestas doctrinales, pero no se atrevía a formular una tesis. Cecilia Mora-Donatto igualmente se muestra favorable al control en Mora-Donatto (2008) pp. 619-645. Así como Muro (2010) quien insiste en la colaboración del Presidente con el Congreso y en la fiscalización y rendición de cuentas.

102 El artículo 93 de la Constitución de la República Dominicana establece que el Congreso Nacional "fiscaliza en representación del pueblo", y "supervisa todas las políticas públicas que implemente el gobierno" (artículo 93.2.f]).

103 La Constitución de Cádiz de 1812, en sus artículos 121 y 122, establecía que el Rey asistirá a la a apertura de las Cortes y hará un discurso en el que les propondrá lo que estime conveniente "y al que el presidente contestará en términos generales”. No veo por qué razones podía contestarse a un Monarca del siglo XIX y no puede responderse a un Presidente democrático de una República. Las instituciones parlamentarias deben transformarse. 
la Constitución estadounidense se ha quedado vieja. De no ser así, el Presidente podría perfectamente contactar con el pueblo directamente a través de los medios de radiodifusión sin necesidad de la mediación de todo el Congreso.

Esta herramienta mexicana debería evolucionar y transformarse como ya lo hizo en sus inicios en Estados Unidos cuando Woodrow Wilson volvió a leer personalmente el informe escrito en 1913 en vez de contentarse con enviarlo o, más tarde en 1923, cuando empezó a transmitirse por los medios de comunicación. De hecho desde 1970, la oposición emite allí una respuesta al discurso presidencial a través de los medios. Me pregunto por qué seguir haciéndolo fuera de la Casa y para qué sirve entonces un Parlamento. ¿No es esto una ficción? Las técnicas parlamentarias no pueden permanecer inmóviles según hemos razonado antes en línea de principios.

Restaría por resolver todo lo demás. Pues la Constitución en el texto de 1917 no especificaba un procedimiento. Me pregunto qué tipo de procedimiento parlamentario debería preverse: probablemente un debate muy general y no pormenorizado. Quién debe ofrecer esas respuestas, el Presidente o más tarde los Secretarios, y con qué extensión, porque es cierto que la discusión de un informe anual no puede sustituir los controles habituales de cada período de sesiones, y el debate debería ser relativamente breve. No falta quien cree que son mejores comparecencias frecuentes a informes anuales de carácter extraordinario. Asimismo, con qué intensidad debería producirse la información y el control, quizás debería contentarse con una información general y el debate, un breve intercambio de opiniones con los legisladores. La separación de poderes no puede querer decir ausencia de control-información, pero caben diversas soluciones. El presidencialismo iberoamericano no debería impedir las relaciones entre órganos siguiendo un entendimiento rígido y separatista de la separación de poderes.

Sin embargo, tras distintos conflictos políticos (algunos diputados impidieron en 2006 que el Presidente Fox entrara en el Congreso), la evolución del informe presidencial en México no ha ido en este sentido lógico sino todo lo contrario. Desde ese incidente, el Presidente dejó de comparecer en el Congreso para dar lectura al mismo, el informe simplemente se entrega por escrito por el secretario de Gobernación, y la máxima autoridad se comunica directamente con la nación a través de spots en radio y televisión. ¿Es esto razonable en nuestros días o supone un estilo presidencial autoritario? La presidencia de la Cámara ha pedido que el Presidente vuelva a la Cámara y se alcance una forma de diálogo y no de enfrentamiento de poderes.

No obstante, el artículo 69 de la Constitución fue finalmente reformado en 2008 y posteriormente en 2014, estableciéndose que, en la apertura de sesiones ordinaria del primer período de cada año del Congreso, el Presidente de la República presentará un informe por escrito en el que manifieste el estado general que guarda la administración pública del país; y, en las sesiones extraordinarias, informará de los motivos de la convocatoria. Se agrega que cada una de las Cámaras realizará el análisis del informe y podrá solicitar ampliaciones mediante preguntas escritas y citar a los Secretarios de 
Estado y a otras autoridades para que comparezcan y rindan informe; la regulación del procedimiento se deja a la Ley del Congreso y a sus reglamentos.

A mi parecer, la nueva previsión de procedimiento es en abstracto bastante correcta y supone un avance frente al texto anterior, siempre y cuando se interprete por convención en el sentido de que no baste con la presentación escrita del informe -lo que sería una transgresión de las normas de corrección o cortesía entre órganos constitucionales-, volviéndose a la lectura y comparecencia inicial, aunque las respuestas gubernamentales a las preguntas parlamentarias las realicen los miembros del Gobierno y no el Presidente. Es un camino en el medio de dos entendimientos.

Otro problema semejante ocurre respecto de las comparecencias ministeriales en México. La Constitución (artículo 93) obliga a los Secretarios de despacho a dar cuenta del estado de sus respectivos departamentos; y permite a la Cámaras citarlos para que informen "bajo protesta de decir verdad" o para que respondan a preguntas e interpelaciones; y estas obligaciones no se someten a limitaciones constitucionales $\operatorname{expresas}^{104}$. En la práctica, los miembros del Gobierno informan a las comisiones del Congreso, pero -al parecer según Valadés ${ }^{105}$ - la aplicación ha sido discontinua y se discute si debería normalizarse. Podría bastar -afirma- con generar un uso o costumbre.

Si volvemos la vista a la lógica de un Gobierno constitucional moderado y representativo, cómo puede justificarse en el siglo XXI que los departamentos ministeriales y secretarias no informen continuadamente al Parlamento sobre la acción de gobierno y se sometan a la discusión con las minorías. De no ser así, un Parlamento no merecería el nombre de Parlamento, su nomen iuris, al carecer de las facultades que hacen reconocible a la institución. Ese entendimiento separatista del presidencialismo ha devenido obsoleto y responde a argumentos del primer liberalismo y propios de otros siglos cuando la sociedad apenas tenía un Estado. La Constitución no establece expresamente diques o frenos y con ello debería bastar. Pero la verdadera razón democrática creo es de más peso. Sin información no puede construirse por los parlamentarios la relación de representación política con los electores, ni generarse opinión pública, y este no puede ser un resultado querido por una separación constitucional de poderes, aunque sea rígida. El Gobierno no puede colocar al Parlamento en una situación en que no pueda ejercer sus funciones mediante un entendimiento de las competencias propias que impida ejercer sus competencias al otro. La presidencia y el Gobierno deben colaborar en el ejercicio de las funciones de las Cámaras salvo excepciones razonables que reclaman una motivación reforzada.

En todo caso, si el Presidente no comparece en el Congreso para leer su informe anual y los Ministros obstaculizan sus comparecencias, o las normas limitan en exceso la frecuencia de este instrumento, es fácil percibir que se produce una situación

Sigo en esto a VALADÉs (1998) p. 380 y ss, epígrafe "Comparecencias de los miembros del Gabinete e integración de comisiones de investigación". 
de bloqueo institucional que no beneficia a nadie. Si no se quiere que el Presidente responda ante el Parlamento en virtud de su elección directa y legitimidad popular, al menos deberían hacerlo con habitualidad los miembros del Gobierno, que carecen de esa legitimidad democrática directa, para mantener una relación fluida entre los órganos supremos. Por lo demás, la responsabilidad diferida, difusa del Presidente y pospuesta hasta las nuevas elecciones por el término tasado, no solventa bien el problema de qué hacer mientras tanto, como se evidencia cuando la presidencia mengua en legitimidad y apoyos según las encuestas.

De forma complementaria, el mismo artículo 93, párrafo $3^{\circ}$, de la Constitución de México prevé la creación de Comisiones parlamentarias de investigación a instancias de las minorías (una cuarta parte de los diputados y la mitad de los senadores), pero solo en relación con "organismos descentralizados y empresas de participación estatal mayoritarias", debiendo enviarse el resultado de las investigaciones al ejecutivo federal.

Son evidentes las restricciones que este complejo precepto constitucional contempla. Pese a la evolución que han supuesto varias reformas del mismo, hasta el punto de que autores como Valadés y Barceló califican esas transformaciones de verdadera "parlamentarización" del sistema presidencial ${ }^{106}$. Pero siguen existiendo obstáculos al control. ¿Qué sentido constitucional tienen esas confusas restricciones? ¿A qué bien constitucional sirve mantener áreas de la acción de gobierno exentas de control? "On behalf of what?" como hemos visto se preguntaba Ackerman.

\section{Conclusiones}

Es metodológicamente posible -y deseable- comparar presidencialismo y parlamentarismo en materia de controles parlamentarios, pese a las diferencias y oposiciones tradicionales, y construir normas e interpretarlas con voluntad de mejorar los instrumentos de control, muchos de ellos semejantes en ambos continentes, así como intercambiar experiencias enriquecedoras en la solución de conflictos. Algunas normas constitucionales y muchas normas de los Reglamentos parlamentarios reflejan ya esta tendencia. Por más que deba operarse con mucha cautela.

Esta conclusión hace que el debate sobre ambos sistemas de gobierno deba contemplarse de una manera más matizada y realista. El deslinde actual del binomio presidencialismo parlamentarismo, como tipos ideales, debe tener en cuenta la multiplicidad de sistemas presidenciales y semipresidenciales, de confusa diferenciación, que diseñan actualmente las normas constitucionales y parlamentarias en Iberoamérica. El presidencialismo originario estadounidense es antiguo y difícilmente exportable, y el presidencialismo iberoamericano se ha ido parlamentarizando en diversos grados. Esta evolución es natural y hace pensar en la existencia de un continuum en la comprensión del binomio presiden-

106 VAladÉs (1998) p.381. También Daniel A. Barceló (2016) capítulo “... El poder ejecutivo del Estado”, en especial, p. 258 
cialismo/parlamentarismo donde caben distintos escalones y diferencias de grado más cuantitativas que cualitativas.

Se advierten tres tendencias: la presidencialización y racionalización del parlamentarismo europeo, la parlamentarización del presidencialismo iberoamericano, y la relativa continuidad e influencia comparada de los Reglamentos y prácticas parlamentarias por encima de fronteras.

Pero pluripartidismo extremado, representación proporcional, y un entendimiento absolutista de la separación de poderes presidencial, que impida los controles parlamentarios, son rasgos que pueden resultar incompatibles, y, en todo caso, componen un escenario demasiado complejo que puede generar riesgos de gobernabilidad y peligros para la libertad y la democracia representativa. La solución más sencilla para reducir esa complejidad es deshacerse del tercer ingrediente y abandonar un entendimiento personalista y separatista en exceso de la separación de poderes en el presidencialismo -que no garantiza bien constitucional alguno-, flexibilizando su entendimiento hasta donde sea posible.

Es precisa una colaboración y solidaridad entre poderes en cualquier esquema de gobierno constitucional, y el Parlamento debe, por definición, controlar al Gobierno en una democracia representativa, también en el presidencialismo moderno. La duración fija del mandato presidencial y la voluntad inicial de que el Presidente responda de forma diferida ante el electorado hacen difícil la presencia de mecanismos de control-responsabilidad política, pero podría bastar con reforzar o implementar mecanismos parlamentarios de control-fiscalización a instancias de la oposición y las pequeñas minorías. Ya se está haciendo y toda buena teoría debe integrar la realidad. Hay un amplio elenco de herramientas de control posibles y deben seleccionarse y reforzarse aquéllas más adecuadas a las necesidades de cada Parlamento.

Responsabilidad política de los miembros del Gobierno no quiere decir necesariamente el "cese" del titular del cargo, rendir cuentas -someterse al control- supone comparecer en el Parlamento, explicarse, contestar y debatir con las minorías, con contradicción y publicidad, para verificar la acción de gobierno y mantener informados a los ciudadanos, creando opinión pública libre.

Pero, sin control parlamentario, no puede existir democracia representativa; tampoco en el presidencialismo iberoamericano contemporáneo que ha sufrido una seria transformación.

\section{Referencias bibliográficas}

Ackerman, Bruce (2005): The failure of the founding fathers. Jefferson, Marshall and the rise of presidentialism, Harvard U.P.

Ackermann, Bruce (2000): “The new separation of powers" en Harvard Law Review, volumen 13 , enero, $n^{\circ} 3$, pp. 633-725.

Amato, Giuliano (1968): L'ispezione politica del Parlamento, Giuffrè,. 
Амato, Giuliano (1991): "Il sistema presidenziale, un remedio all' eccesso di partitocrazia” en Il Politico, no 158.

Aragón, Manuel (1986): "El control parlamentario como control político” en : Revista de Derecho Político, n² 23, pp. 9 y ss;

Aragón, Manuel (1994): Gobierno y Cortes, Instituto de Estudios Económicos, Madrid.

Aragón, Manuel (1998): “Sistema parlamentario, sistema presidencial y dinámica entre los poderes del Estado. Análisis comparado" en Parlamento y control del ejecutivo, V Jornadas de la Asociación Española de Letrados de Parlamentos, Aranzadi, Pamplona.

BAR, Antonio (1983): El Presidente del Gobierno en España : encuadre constitucional y práctica política, Civitas, Madrid.

Barbera, Augusto (1999): I Parlamenti, Laterza, Bari.

BARCELó, Daniel A. (2016): Teoría del federalismo y del derecho constitucional estatal mexicano, UNAM, México D.F.

Barceló, Daniel y Valadés, Diego (coord.) (2016): Gobierno de coalición. Estudio sobre el sistema presidencial mexicano que contiene el anteproyecto de ley, Cámara de Diputados- CEDIP-UNAM, México DF..

Bustos, Rafael (2001): La responsabilidad política del Gobierno: ¿realidad o ficción?, COLEX.

Carducci, Michele (1996): Controllo parlamentare e teorie costituzionali, Cedam, Padova.

Carpizo, Jorge (1978): El presidencialismo mexicano, siglo XXI, Madrid.

Carpizo, Jorge (2000): "México. ¿̨istema presidencial o parlamentario? En Diego

Valades y José María Serna: El gobierno en América Latina. ¿Presidencialismo o parlamentarismo?, UNAM, México.

Carpizo, Jorge (2007): Concepto de democracia y sistema de gobierno en América Latina, UNAM, México.

Carrillo, Marc (2016): "Parlamento y Gobierno en funciones” en diario La Ley, nº 870.

Chavez, Efrén (2002): "Algunas propuestas de modificación al formato del informe presidencial en México" en Boletín Mexicano de Derecho Comparado, n 105, pp. 817-857,

Chimenti, Carlo (1974): Il controllo parlamentare nell'ordinamento italiano, Giuffrè, Milán.

Embid IRUjo, Antonio (2014): "Norma, economía y lenguaje en el Derecho de la crisis económica: el control judicial de la actividad administrativa en la economía. Algunas reflexiones” en Documentación Administrativa: Nueva Época, nº1.

EMBID IRUjo, Antonio (1992): "El control parlamentario del Gobierno y el principio de la mayoría parlamentaria. Algunas reflexiones” en Revista de las Cortes Generales, n² 25.

Epstein, L. D. (1968): “Parliamentary government” en International Encyclopedia of the Social Sciences, The Macmillan Company, vol. II. 
FERnÁNDEZ SARASOLA, Ignacio (2000): “El control parlamentario y su regulación en el ordenamiento español” en Revista Española de Derecho Constitucional, n 60, pp. 89 ss.

Fernández Sarasola, Ignacio (2012): Reglamentos parlamentarios (1810-1977), Iustel, Madrid.

FERRARI, Giuseppe (1953): Gli organi ausiliari, Giuffrè.

Finer, Samuel (1976): “The individual responsibility of Ministers” en: Public Administration, vol. XXXIV, p. 393, p

G. Calabresi \& y Kyle BAdy, Steven: "Is the separation of powers exportable?" en Harvard Journal of Law and Public Policy, vol. 33, pp. 5-16.

G. CALABRESI, Steven (1998): “An agenda for constitutional reform” en Constitutional stupidities, constitutional tragedies, William N. ESKRIDGE JR \& SANFORD LEVINSON (eds.), Murphi Institute of Political Economy, NUY Press, p. 22 y ss.

Galeotti, Sergio (1962): “Controlli costituzionali” en Enciclopedia del diritto, Giuffrè, $\mathrm{X}$, Milano.

Galizia, Mauro (1972): Studi sui rapporti fra Parlamento e Governo, Giuffré, Milán.

García Escudero, Piedad (2011): "El parlamentario individual en un parlamento de grupos: la participación en la función legislativa” en Teoría y realidad constitucional, no 28, pp. 205-242

García Fernández, Javier (1994): "La función de control del Parlamento sobre el Gobierno. Notas sobre su configuración jurídica” en: Revista de las Cortes Generales, No 31, 1994, Pp. 31 Y Ss; Y

GARCÍA FERnÁNDEZ, Javier (1997): "El control parlamentario desde la perspectiva del Gobierno" en: Cuadernos de Derecho Público, n² 2, pp. 195 y ss.

García Morillo, Joaquín (1985): El control parlamentario del Gobierno en el ordenamiento español, Congreso de los Diputados, Madrid.

García Morillo, Joaquín y Montero, José Ramón (1984): El control parlamentario, Tecnos, Madrid.

García Roca, Javier (1985): “El sistema de Gobierno parlamentario en el País Vasco. Moción de censura individual y derecho a la disolución anticipada” en Revista de Estudios Políticos, n46-47.

García Roca, Javier (1997): "El control del Gobierno desde la perspectiva individual del parlamentario (y a la luz del art. 23.2 de la Constitución)" en: Problemas actuales del control parlamentario, VI Jornadas de Derecho Parlamentario (1995), Congreso de los Diputados, Madrid.

García Roca, Javier (1999): Cargos públicos representativos (Un estudio del art. 23.2 $\mathrm{CE})$, Aranzadi, Pamplona. 
García Roca, Javier (2000): “Del principio de la división de poderes” en: Revista de Estudios Políticos, n 108 , pp. 41 y ss.

García Roca, Javier (2005): “La fragilidad de los Ministros (de su competencia y responsabilidad directas)" en VVAA: Gobierno y Constitución, Pablo Lucas Murillo (coord.), Actas del II Congreso de la Asociación de Constitucionalistas de España (ACE), Tirant lo Blanch, Valencia.

García Roca, Javier (2014): “El desarrollo de la comparación jurídica como ciencia y como materia en la enseñanza en España” en Revista General de Derecho Público Comparado, $\mathrm{n}^{\circ} 14$.

García Roca, Javier y IBRIDo, Renato (2013): “El control parlamentario en Italia.Un estudio comparado sobre el concepto y algunas de sus mejores prácticas: el Comité para la Legislación y la Comisión de Presupuestos" en: El control del gobierno en democracia, Francesc PAU (dir.), Asociación Española de Letrados de Parlamentos, Tecnos, Madrid.

GARGARELLA, Roberto (1992):"El presidencialismo como sistema contramayoritario" en S. Nino, Carlos y Gargarella, Roberto y otros (1992): El presidencialismo puesto a prueba -con especial referencia al sistema presidencial latinoamericano-, Centro de Estudios Constitucionales, Madrid.

Giannini, Massimo Saverio (1965): Corso di Diritto Amministrativo, Giuffrè, Milán.

Giannini, Massimo Saverio (1974): "Controllo: nozioni e problemi” en : Rivista trimestrale di diritto pubblico.

Gouet, Yvon (1932): "Qu'est-ce que le régime parlamentaire” en : Revue de Droit Public, pp. 179-243;

Hamilton, Alexander, Madison, James y Jay, John (1943): El federalista, Fondo de Cultura Económica, $5^{\mathrm{a}}$ reimpresión, México.

JEFFERSON, Thomas (1801): A manual of parliamentary practice for the use of the Senate of the United States, 1a edición de 1801, 2a edición de 1812.

KRIELE, Martin (1980): Introducción a la teoría del Estado, Depalma.

Krsticevic, Viviana (1992): "Presidencialismo en América Latina” en S. Nino, Carlos y GARGARELLA, Roberto y otros (1992): El presidencialismo puesto a prueba -con especial referencia al sistema presidencial latinoamericano-, Centro de Estudios Constitucionales, Madrid.

LaClaU, Ernesto (2005): La razón populista, Fondo de Cultura Económica, Buenos Aires.

LeibHolz, Gerard (1971): La función controladora del Parlamento en las democracias de partidos del siglo XX, Instituto de Estudios Políticos, Madrid.

Liz, Juan J y Nohlen, Dieter y otros (1993): Reformas al presidencialismo en América Latina. ¿Presidencialismo vs. Parlamentarismo”, Comisión Andina de Juristas, Editorial Jurídica Venezolana, Caracas. 
López Aguilar, Juan Fernando (1991): Minoría y oposición en el parlamentarismo. Una aproximación comparatista, Congreso de los Diputados, Madrid.

López BASAguren, Alberto (2015): "Hung parliament will make it difficult to push forward the political reform Spain needs", Posted on December 29, The Constitution Unit, www.constitution-unit.com

López Guerra, Luis (1996): "El control parlamentario como instrumento de las minorías" en: Anuario de Derecho Constitucional y Parlamentario, no 8.

Lupo, Nicola (2009): "La funzione di controllo parlamentare nell'ordinamento italiano" en Amministrazione in Cammino, http://www.amministrazioneincammino. luiss.it.

Mainwaring, Scott y Soberg Shugart, Mathew (1997): Presidentialism and democracy in Latin America, Cambridge U. P.

Manzella, Andrea (1970): I controlli parlamentari, Giuffrè, Milán.

Manzella, Andrea (1991): Il parlamento, Il Mulino, Bolonia

MaY, Erskine (1989): Parliamentary practice. Treatise on the Law, privileges, proceedings and usage of Parliament, Butteworths, Londes.

Mckay, William y Johson, Charles W.: Parliament and Congress: representation and scrutiny in the twenty-first century, Oxford U. Press.

Mirkine-Guetzevitch, Boris (1931): Estudio preliminar a Las nuevas Constituciones del mundo, Ed. España, Madrid, $2^{a}$ ed.

Mirkine-Guetzevitch, Boris (1934): Las nuevas constituciones del mundo, estudio preliminar, Ed. España, Madrid.

Mirkine-Guetzevitch, Boris (1934): Modernas tendencias del Derecho Constitucional, Ed. Reus, Madrid.

Molas, Isidre e PITARCH, Ismael (1987): Las Cortes Generales en el sistema parlamentario de Gobierno, Tecnos, Madrid.

Mora-Donatto, Cecilia (2001): "Instrumentos constitucionales para el control parlamentario" en Cuestiones constitucionales, UNAM, México.

Mora-Donatto, Cecilia (2008) igualmente se muestra favorable al control: "La reforma al formato del informe presidencial: ¿parálisis o autismo legislativo? en La ciencia del Derecho Procesal Constitucional. Estudios en homenaje a Héctor FixZamudio, tomo XI,

Moretti, Renato (2005): "Attività informative, di ispezione, di indirizzo e di controllo" en

T. Martines-G-Silvestri-C. De Caro-V. Lippolis-R. Moretti (cur.), Diritto parlamentare, Giuffrè, Milán.

Muro, Eliseo (2010): "El nuevo formato del informe presidencial, un instrumento de control parlamentario en México" en Homenaje al Dr. Emilio O. Rabasa, UNAM, Mèxico. 
Navas, Luis Felipe (2014): El núcleo de la función representativa parlamentaria: una propuesta para la justicia constitucional mexicana, UCM.

Nogueira, Humberto (1988): "Análisis crítico del presidencialismo. Los regímenes presidenciales de América Latina” en Presidencialismo vs. Parlamentarismo. Materiales para el estudio de la reforma constitucional, EUDEBA, Buenos Aires.

NoHLEN, Dieter (1991): "Presidencialismo versus parlamentarismo en América Latina" en Revista de Estudios Políticos, $\mathrm{n}^{\circ} 74$.

PreSnO, Miguel Ángel (1999): “Sistema de partidos y control parlamentario” en: Revista de las Cortes Generales, no 46, pp. 94,

RedsLob, Robert (1923): “Le régime parlamentaire en Allemagne” en Revue de Droit Public, pp. 511-539.

REDSLOB, Robert (1924) : Le régime parlamentaire. Étude sur les institutions d'Angleterre, de Belgique, de Hongrie, de Suède, de France, De Tchécoslovaquie, de l'Empire allemand, de Prusse, de Bavière et d'Autriche, Marcel Girard, Paris.

Rescigno, Giuseppe Ugo (1968): La responsabilità politica, Giuffrè, Milán.

Rescigno, Giuseppe Ugo (1979): Corso di Diritto Pubblico, Il Mulino, Bolonia. Reimpreso, edición 1984.

GARGARELLA, Roberto (1992): "El presidencialismo como sistema contramayoritario" en: S. Nino, Carlos y Gargarella, Roberto y otros, El presidencialismo puesto a prueba -con especial referencia al sistema presidencial latinoamericano-, Centro de Estudios Constitucionales, Madrid.

Rubio, Francisco (1993): "El control parlamentario" en: La forma del poder, CEC, Madrid.

S. Nino, Carlos y Gargarella, Roberto y otros (1992): El presidencialismo puesto a prueba -con especial referencia al sistema presidencial latinoamericano-, Centro de Estudios Constitucionales, Madrid.

SAbSaY, Daniel A. (1992): "El semipresidencialismo: una visión comparada" en S. Nino, Carlos y Gargarella, Roberto y otros (1992): El presidencialismo puesto a prueba -con especial referencia al sistema presidencial latinoamericano-, Centro de Estudios Constitucionales, Madrid.

SÁnChez Navarro, Ángel (1997): La oposición parlamentaria, Madrid, Congreso de los Diputados.

Santaolalla, Fernando (1982): El Parlamento y sus instrumentos de información (preguntas, interpelaciones y Comisiones de investigación, EDERSA, Madrid.

Santaolalla, Fernando (1984): Derecho Parlamentario Español, Ed Nacional, Madrid.

SAntaolalla, Fernando (1987): "La función de control y la ciencia del Derecho Constitucional” en: Revista de las Cortes Generales, no 12, pp. 219 y ss; 
Sonnheimer, Kurt (1980): “Treinta años de parlamentarismo alemán” en: Revista de Estudios Políticos, no 14, pp. 5-21; y

STARCK, Christan (2012): "El sistema de gobierno parlamentario en Alemania como factor de estabilidad” en: Revista de las Cortes Generales, nº 87, pp. 101-119.

Torres, Ignacio (1987): Los órganos de gobierno de las Cámaras, Congreso de los Diputados, Madrid.

VALAdÉs, Diego (1998): El control del poder, Porrua-UNAM, México, 2ª ed. 2006.

Vergottini, Giuseppe de (1968): “Opposizione parlamentare” en Enciclopedia del Diritto, Giuffrè, Milán, XVII, pp. 388 y ss;

Vergottini, Giuseppe de (1973): Shadow cabinet. Saggio comparativo sul rilievo costituzionale dell'opposizione nel regime parlamentare britanico, Giuffré, Milán.

Vergottinil, Giuseppe de (1993): "La garanzia della funzione di opposizione come elemento unificante delle forme di governo" en: Diritto Costituzionale Comparato, 4a ed., CEDAM, Padua, pp. 403-417.

VVAA (1985): Instrumentos de información de las Cámaras parlamentarias, CEC, Madrid.

VVAA (1990): El Parlamento y sus transformaciones actuales, Jornadas de la Asamblea Tecnos, Regional de Murcia.

VVAA (2005): Gobierno y Constitución, Pablo Lucas Murillo (coord.), Actas del II Congreso de la Asociación de Constitucionalistas de España (ACE), Tirant lo Blanch, Valencia.

Woodhouse, Diana (1993): "Ministerial responsability in the 1990s. When do ministers resign?” en: Parliamentary Affairs, 46 (3), pp. 277-292. 